\title{
A dynamic, climate-driven model of Rift Valley fever
}

\author{
Joseph Leedale, ${ }^{1}$ Anne E. Jones, ${ }^{2}$ Cyril Caminade, ${ }^{2,3}$ Andrew P. Morse ${ }^{1,3}$ \\ 'School of Environmental Sciences, University of Liverpool, Liverpool; ${ }^{2}$ Department of \\ Epidemiology and Population Health, Institute of Infection and Global Health, University \\ of Liverpool, Liverpool; ${ }^{3}$ National Institute for Health Research, Health Protection \\ Research Unit in Emerging and Zoonotic Infections, Liverpool, UK
}

\begin{abstract}
Outbreaks of Rift Valley fever (RVF) in eastern Africa have previously occurred following specific rainfall dynamics and flooding events that appear to support the emergence of large numbers of mosquito vectors. As such, transmission of the virus is considered to be sensitive to environmental conditions and therefore changes in climate can impact the spatiotemporal dynamics of epizootic vulnerability. Epidemiological information describing the methods and parameters of RVF transmission and its dependence on climatic factors are used to develop a new spatio-temporal mathematical model that simulates these dynamics and can predict the impact of changes in climate. The Liverpool RVF (LRVF) model is a new dynamic, process-based model driven by climate data that provides a predictive output of geographical changes in RVF outbreak susceptibility as a result of the climate and
\end{abstract}

Correspondence: Joseph Leedale, School of Environmental Sciences, University of Liverpool, Liverpool L69 3GE, UK.

Tel: +44.151.7950382.

E-mail: j.leedale@liverpool.ac.uk

Key words: Rift Valley fever; Epidemiology; Climate; Mathematical modelling; Vector-borne diseases.

Acknowledgements: the authors acknowledge funding support from the HEALTHY FUTURES EU-FP7 project (grant agreement 266327). The authors would like to thank Bernard Bett and John Gachohi for their contribution to parameterisation of the Liverpool Rift Valley fever model and discussions about Rift Valley fever. CC also acknowledges support by The Farr Institute for Health Informatics Research (MRC grant: MR/M0501633/1).

Contributions: JL and AEJ equally contributed to this work.

Conflict of interest: the authors declare no potential conflict of interest.

Note: see online Appendix for parameterisation of the host module and vector model specification.

Received for publication: 24 June 2015.

Revision received: 3 November 2015.

Accepted for publication: 11 November 2015.

(C) Copyright J. Leedale et al., 2016

Licensee PAGEPress, Italy

Geospatial Health 2016; 11(s1):394

doi:10.4081/gh.2016.394

This article is distributed under the terms of the Creative Commons Attribution Noncommercial License (CC BY-NC 4.0) which permits any noncommercial use, distribution, and reproduction in any medium, provided the original author(s) and source are credited. local livestock immunity. This description of the multi-disciplinary process of model development is accessible to mathematicians, epidemiological modellers and climate scientists, uniting dynamic mathematical modelling, empirical parameterisation and state-of-the-art climate information.

\section{Introduction}

Rift Valley fever (RVF) is a vector-borne, zoonotic disease characterised by abortion storms and increased mortality rates in livestock. This disease is caused by the RVF virus of the genus Phlebovirus in the family Bunyaviridae. RVF mainly affects domestic animals such as cattle, goats, sheep and camels, among others (Meegan and Bailey, 1988). Epizootics of RVF have occurred throughout Africa following periods of extensive rainfall and subsequent flooding, promoting an increase in the activity of associated mosquito vectors (Bird et al., 2009). The virus has public health impacts as it can also be transmitted to humans via infectious mosquito bites or, as in the majority of cases, direct contact with the viraemic blood of an infected animal (via slaughter and butchery for example see Gerdes, 2002). An outbreak of RVF can also be economically devastating for the cattle owners and businesses involved in the trading of livestock due to infection and decimation of the herd (Peyre et al., 2014).

Since initial identification of the virus in the Rift Valley of Kenya in 1931 (Daubney et al., 1931), RVF has become endemic in eastern Africa with severe epizootics occurring periodically. RVF epizootics in this area of Africa appear to correlate with El Niño/Southern Oscillation (ENSO) climate phenomena as anomalous warming sea surface temperatures in the eastern equatorial Pacific Ocean and western equatorial Indian Ocean lead to increased rainfall in the Horn of Africa (Linthicum et al., 1999; Anyamba et al., 2009). The frequent outbreaks in eastern Africa are also believed to be associated with regional susceptibility following diminished host immunity. These inter-epizootic timescales are therefore linked to the natural mortality rates of RVF hosts as well as climatic drivers that can initiate major outbreaks in vulnerable populations (Anyamba et al., 2012). Other factors that contribute to local RVF outbreaks include topography, soil type (hydromorphic dambos favour breeding sites in the region), host/vector population density and multiple lineages of the virus (Nguku et al., 2010; Pepin et al., 2010; Nderitu et al., 2011). Here, we focus on the impact of climate variables on RVF, since they are the only spatial data available over a long time period and for which future scenarios based on climate models are also available.

In order to determine the climatic conditions that make a particular region vulnerable to outbreaks of RVF, the relationship between the population dynamics of the RVF vectors and the local environment must be understood. Anomalously high rainfall in eastern Africa has 
long been associated with RVF outbreaks due to an increase in temporary water-bodies serving as vector habitats and the ensuing surges in numbers of infected mosquitoes. The RVF virus can be transmitted by over 30 mosquito species and in different regions of Africa there appears to be some variation between species with respect to the dominant vectors of RVF transmission (Fontenille et al., 1998). However, Aedes and Culex genera are considered to be the main vectors of the disease (Pepin et al., 2010; Abdo-Salem et al., 2011). Aedes mosquitoes are the primary vectors of RVF as they can transmit the virus transovarially to their offspring (Linthicum et al., 1985; Pepin et al., 2010), whereas Culex vectors must bite an infectious host in order to become infected. Rainfall conditions influence the population dynamics of Aedes and Culex due to their breeding site preferences. Aedes mosquitoes oviposit on damp ground at the sloped edge of wet depressions. These eggs require inundation of water in order to hatch but must first undergo a dehydration period. If required, Aedes eggs can remain viable by resisting desiccation in dry conditions for months before rehydration occurs (Mondet et al., 2005; Pepin et al., 2010) and therefore have the potential to act as resevoirs of RVF (Porphyre et al., 2005) via transovarial transmission (Davies and Highton, 1980; Rolin et al., 2013). Culex lay their eggs directly on the surface of water bodies and as such increase greatly in abundance during periods of heavy rainfall and flooding and can also therefore amplify any RVF transmission (Bird et al., 2009; Anyamba et al., 2010). A recent statistical modelling study which correlated the spatial distribution of the RVF vector Culex tritaeniorhynchus with bioclimatic variables and land use types highlighted the importance of rainfall during the warmest months of the year and the presence of wet muddy substrate (Sallam et al., 2013).

Variation in the viraemia of RVF virus across multiple species of mosquito from region to region is dependent on many underlying factors such as the relative distribution and size of indigenous populations, presence or absence of an epizootic and the timing and method of field measurements. For example, Aedes vexans and Aedes dalzielei were found to be the most competent RVF vectors in Senegal (Zeller $e t$ al., 1997) with Aedes vexans being the most infected in West Africa generally. However, it was mainly vector species of the Culex genus (Culex poicilipes, Culex quinquefasciatus, Culex tritaeniorhynchus and Culex antennatus) that were found in Mauritania following the RVF outbreak in 2003, with only Culex poicilipes carrying the RVF virus, but this was due to the relatively late measurements in the context of the evolution of an outbreak (Faye et al., 2007). Aedes mcintoshi and various Culex species (Culex zombaensis, Culex poicilipes, Culex bitaeniorhynchus, Culex quinquefasciatus, Culex univittatus) were heavily involved in RVF virus transmission in Kenya and Tanzania during the large 19971998 outbreak (Himeidan et al., 2014). The 2000 RVF outbreak in Saudi Arabia is believed to have come from East Africa and transmitted by Aedes vexans arabiensis and Culex tritaeniorhynchus although only Culex competence was confirmed (Jupp et al., 2002; Sallam et al., 2013). We conclude that the important distinction between Aedes and Culex is in their respective roles at different points during RVF outbreaks and the potential reservoir behaviour of Aedes rather than relative viraemia of specific species.

Localised, low-level enzootic transmission of the RVF virus can take place under relatively normal rainfall (Bird et al., 2008). This underlying circulation of the virus is supported by the transovarial transmission of Aedes and the dormancy of infected eggs during dry spells. Under the right environmental conditions, such as uncharacteristically late, heavy rainfall preceded by a dry period at the end of a rainy season, low-level transmission can be amplified and a major outbreak of the disease can occur (Ndione et al., 2003, 2008; Nderitu et al., 2011; Caminade et al., 2014b). This epizootic transition follows a sequence of large-scale mosquito proliferation events as large numbers of dormant infected Aedes emerge following flooding followed by a great increase in the Culex population due to the flooding-induced emergence of abundant favourable breeding sites (Bicout and Sabatier, 2004).

Previous RVF modelling efforts using dynamic mathematical models have largely focused on the epidemic stability of susceptible host populations when the virus is introduced (Gaff et al., 2007; Mpeshe et al., 2011; Niu et al., 2012). These studies comprise theoretical exercises concentrating purely on transmission during different epidemiological states independent of climate. The effects of the environment on mosquito dynamics have been included in some other recent RVF modelling that investigate the fluctuating effects of regional seasonality using a simple oscillating temperature function (Fischer et al., 2013), spatial effects via weighted contact networks (Xue et al., 2012), hydrology (Soti et al., 2012) and effects of vaccination interventions (Chamchod et al., 2014). However, quantitative risk assessment of the impact of climate change on RVF dynamics in Africa has not been carried out. These models do not account for long-term impacts of changing climate patterns and fluctuating immunity with regional vulnerability to epizootics based on historical and projected climate data. In cases where climate information has been used for previous modelling, it is based on simplified fluctuating analytical functions and there is no evidence of the nuanced relationships between vector larval development and temperature or Aedes emergence and rainfall dynamics. Neither do these studies account for the significant differences between young and adult hosts with respect to infectioninduced mortality (Bird et al., 2009).

There is a clear need for a quantitative, predictive, dynamic mathematical model that describes the complex relationship between climatic factors, vector life-cycles and host epidemiology through explicit modelling of the underlying processes involved. The University of Liverpool Rift Valley fever model (LRVF) was developed in response to this need as part of the FP7 projects QWeCI and HEALTHY FUTURES (HF), which aimed to improve climate-health early warning and assess the health impacts of climate change respectively. The LRVF model was conceived as a dynamic, climate-driven model of RVF based on published parameter and field-based data compiled within the HF project. Simulations were performed for the East African Community (EAC) region and validation of the model was based on relevant literature information. As well as enhancing current understanding of the underlying processes and drivers of RVF transmission, the eventual intended application of LRVF is to provide quantitative, spatiotemporal information on RVF epidemiology and epizootic susceptibility as part of an early warning system that assesses the impact of climate change on vector-borne diseases in eastern Africa.

\section{Materials and Methods}

The LRVF model describes the dynamics of Rift Valley fever transmission and its dependence on climatic factors (rainfall and temperature). The model (Figure 1A) is mathematically and structurally based on the Liverpool malaria model (LMM) initially developed by Hoshen and Morse (2004). It is a dynamic, process-based model that follows a deterministic compartmental approach to the epidemiology of RVF. In the mathematical model, assumptions of the transmission characteristics of the vector variables are mainly based upon two distinct species, Aedes vexans and Culex pipiens, which are well-documented in the literature. The key motivation for this specification however is a more generalised abstraction based upon significant differences in breeding 
habits and the vertical transmission discovered by a vector of the Aedes genus (Linthicum et al., 1985). Therefore we refer to two generic vector populations for simplicity where the Aedes variable represents the primary vector corresponding to species displaying RVF reservoir characteristics and the Culex variable represents the secondary vector corresponding to amplification species. The host component of the model is subdivided by treating mature and immature livestock as separate dynamic variables due to considerably different transmission characteristics. Infection occurs indirectly, via interaction between the hosts and in this case the two vector populations. Vector and host populations are divided into classes based on their infection status. These classes follow the standard epidemiological nomenclature of susceptible $(S)$, exposed $(E)$ and infectious $(I)$ populations. The host component also includes the recovered $(R)$ class. Recovered hosts maintain lifelong immunity (Wilson, 1994).

Spatiotemporal climate dependence is incorporated into the model via climate-dependent transmission parameters of the vector component. Daily temperature and rainfall values are linked dynamically to the gonotrophic cycle, ovipositioning, larval development and mortality-related parameters. Although the link between RVF outbreaks and vegetation cover favouring vector habitat has been established (Linthicum et al., 1999), here we use the direct approach of considering rainfall as a driving variable in order to mechanistically model vector dynamics. Parameters governing livestock population dynamics have no direct dependence on climatic factors. The model is effectively driven by gridded climate input data and provides an output that indicates which geographical areas are susceptible to increased RVF activity as a result of the state of the climate, e.g. preceding temporal rainfall dynamics in combination with optimal temperature ranges, and predicted current livestock immunity. The host immunity feature of the model adds another layer of complexity whereby the current climate is not sufficient to determine RVF susceptibility but also the past climate, and potential recent transmission events, must be taken into consideration.
The mathematical model was formulated following the creation of a new generalised disease-modelling library, EpiCS. EpiCS (Epidemiological modelling toolkit for Climate Sensitive disease) is a $\mathrm{C} / \mathrm{C}++$ library of generic functions which allows any host or vector process (such as mortality, population growth, biting rate) to be associated with any transmission model structure. The toolkit was tested by recreating the Liverpool Malaria Model. The LRVF model is largely parameterised using literature-based data and data collected as part of the HEALTHY FUTURES project as discussed later.

\section{Host component}

The LRVF model contains age-dependent specification in the host component for a population of livestock susceptible to RVF virus infection via vector biting; livestock are divided into two subpopulations based on age, since immature livestock have a much higher infectioninduced mortality rate. These subpopulations represent neonatal livestock and adult livestock. The case fatality ratios for adult livestock are relatively low and recovery is included in the model for livestock who escape infection-induced death, and attain lifelong immunity. The subpopulations are dynamically coupled via new births and the neonatal mature into adult livestock. The population model is derived such that in the absence of infection both sub-populations have a unique, stable steady state.

The system of equations in Table 1 represents the host component module of LRVF. Neonatal livestock and adult livestock model variables are represented by $X$ and $Y$ respectively. Similarly parameters with $x$ or $y$ subscripts represent parameters pertaining to neonatal and adult livestock. Subscripts $S, E, I$ and $R$ represent epidemiological classes for susceptible, exposed (infected but not yet infectious), infectious and recovered (immune) individuals. Total populations are also defined, $X_{=} X_{S}+X_{E}+X_{I}+X_{R}, Y=Y_{S}+Y_{E}+Y_{I}+Y_{R}, N=X+Y$. Superscripts $A$ and $C$ are used for parameters associated with model vectors Aedes and Culex. Superscripts $t$ and $t+1$ denote the value of the variable at time $t$

Table 1. System of difference equations representing the epidemiological model for the livestock component of the Liverpool Rift Valley fever model and associated parameter definitions.

\begin{tabular}{|c|c|c|c|}
\hline \multirow{2}{*}{\multicolumn{2}{|c|}{ 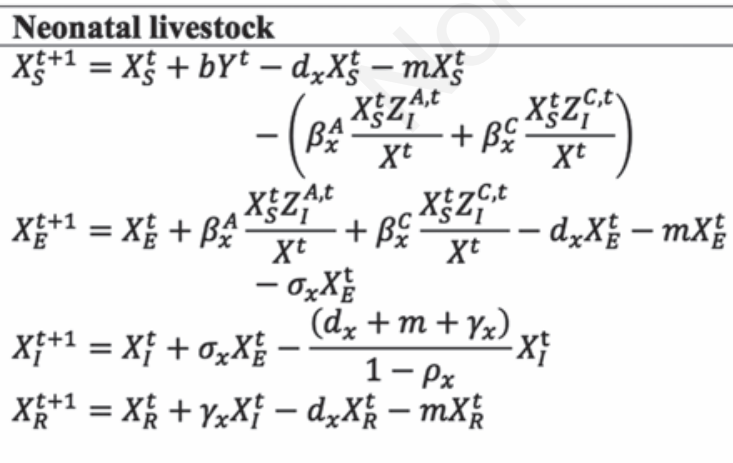 }} & \multirow{2}{*}{\multicolumn{2}{|c|}{$\begin{array}{c}\text { Adult livestock } \\
\begin{array}{c}Y_{S}^{t+1}=Y_{S}^{t}+c+ \\
m X_{S}^{t}-d_{y} Y_{S}^{t} \\
-\left(\beta_{y}^{A} \frac{Y_{S}^{t} Z_{I}^{A, t}}{Y^{t}}+\beta_{y}^{C} \frac{Y_{S}^{t} Z_{I}^{C, t}}{Y^{t}}\right) \\
Y_{E}^{t+1}=Y_{E}^{t}+m X_{E}^{t}+\beta_{y}^{A} \frac{Y_{S}^{t} Z_{I}^{A, t}}{Y^{t}}+\beta_{y}^{C} \frac{Y_{S}^{t} Z_{I}^{C, t}}{Y^{t}}-d_{y} Y_{E}^{t} \\
\quad-\sigma_{y} Y_{E}^{t} \\
Y_{I}^{t+1}=Y_{I}^{t}+m X_{I}^{t}+\sigma_{y} Y_{E}^{t}-\frac{\left(d_{y}+\gamma_{y}\right)}{1-\rho_{y}} Y_{I}^{t} \\
Y_{R}^{t+1}=Y_{R}^{t+1}+m X_{R}^{t}+\gamma_{y} Y_{I}^{t}-d_{y} Y_{R}^{t}\end{array}\end{array}$}} \\
\hline & & & \\
\hline \multicolumn{4}{|c|}{ Host module } \\
\hline$Z_{I}^{A}$ & Infected Aedes & $\sigma_{x}, \sigma_{y}$ & Incubation parameters \\
\hline$Z_{I}^{C}$ & Infected Culex & $\gamma_{x}, \gamma_{y}$ & Recovery rates \\
\hline$d_{x}, d_{y}$ & Basal mortality rates & $\rho_{x}, \rho_{y}$ & Infection-induced mortality probabilities \\
\hline$m$ & Maturation rate & $b$ & Birth rate \\
\hline $\begin{array}{l}\beta_{x}^{A}, \beta_{x}^{C}, \\
\beta_{y}^{A}, \beta_{y}^{C}\end{array}$ & Rates of infection & $c$ & Import rate \\
\hline
\end{tabular}


and $t+1$ days respectively. This is a representative extraction of the module such that the vector component is decoupled for simplicity. Consider here only the values for infected Aedes and Culex in the biting stage of the gonotrophic cycle, $\mathrm{Z}_{\mathrm{I}}^{\mathrm{A}}$ and $\mathrm{Z}_{\mathrm{i}}^{\mathrm{C}}$.

New births are assumed to be proportional to the current size of the total adult livestock population. In order to maintain a robust, idealised population of livestock a constant influx of adult livestock, $c$, is introduced. When the disease is present surplus deaths due to infection must be incorporated. This is implemented via the introduction of an infected removal term that takes into account the probability, $\rho$, of an infected individual dying from the infection before either recovering or dying from natural causes (Keeling and Rohani, 2008):

$$
\begin{gathered}
X_{I}^{t+1}=X_{I}^{t}+\sigma_{x} X_{E}^{t}-\left(d_{x}+m+\gamma_{x}\right) X_{I}^{t}-\frac{\rho_{x}}{1-\rho_{x}}\left(d_{x}+m+\gamma_{x}\right) X_{I}^{t} \\
=X_{I}^{t}+\sigma_{x} X_{E}^{t}-\frac{\left(d_{x}+m+\gamma_{x}\right)}{1-\rho_{x}} X_{I}^{t}
\end{gathered}
$$

and similarly

$$
Y_{I}^{t+1}=Y_{I}^{t}+m X_{I}^{t}+\sigma_{y} Y_{E}^{t}-\frac{\left(d_{y}+\gamma_{y}\right)}{1-\rho_{y}} Y_{I}^{t}
$$

$N$ is constant in the absence of infection, i.e., if $Z_{I}^{A}=Z_{I}^{C}=0$, then $N=N_{C}$ (constant). In order to determine the rate of $c$ we analyse the disease-free equilibria of the system. In the absence of infection the host module can be simplified:

$$
\begin{aligned}
& X^{t+1}=X^{t}+b Y^{t}-\left(d_{x}+m\right) X^{t} \\
& Y^{t+1}=Y^{t}+c+m X^{t}-d_{y} Y^{t}
\end{aligned}
$$

with corresponding steady state(s):

$$
Y^{*}=\frac{c\left(d_{x}+m\right)}{d_{y}\left(d_{x}+m\right)-m b}, X^{*}=\frac{b c}{d_{y}\left(d_{x}+m\right)-m b}
$$

To ensure that $X^{*}$ and $Y^{*}$ are positive we impose the condition

$$
b<d_{y}\left(1+\frac{d_{x}}{m}\right)
$$

This condition is met by enforcing $b=d_{y}$ such that births match the deaths of mature cattle. Thus, if the size of the ideally maintained adult population, $Y^{*}$, is known for a particular site/farm/region, the constant crude import rate $c$ is defined:

$$
c=\frac{Y^{*} d_{y} d_{x}}{\left(d_{x}+m\right)}
$$

\section{Vector component}

Adult Aedes and Culex vectors in the model are divided into three epidemiological classes: susceptible $(S)$, exposed $(E)$ and infectious $(I)$ (Figure 1A). The system of difference equations governing the vector component of the model is given in the Appendix. Rainfall has an important impact on the availability of breeding sites for mosquitoes associated with transmission of the RVF virus. For the two different vector populations, Aedes and Culex, the impact is slightly different and this is represented in the immature vector components of the model. Culex lay their eggs directly on the surface of water bodies and as a result can amplify the RVF virus during flooding. Here the availability of Culex breeding sites is modelled by a simple linear function relating the number of eggs laid per female mosquito to the mean rainfall over the previous ten days. Larval mortality is also modelled using a rainfall function (Table 2A), thereby requiring the persistence of surface water for full maturation of the vector.

In contrast, Aedes oviposit on damp ground at the edges of water bodies but the eggs require a period of dehydration to develop before hatching upon rehydration. The Aedes mosquito population are therefore modelled using a drying/wetting trigger for the egg stage, driven by rainfall, a physically based version of the rainfall criteria used in simpler RVF models (Mondet et al., 2005; Caminade et al., 2011). In LRVF, Aedes eggs require a (configurable) period of $N_{E}$ dry days followed by a re-wetting event before they can proceed to larval and pupal stages (Figure 1B). For example, to determine if the drying and wetting conditions (respectively) have been met for a given day for Aedes, rainfall averages $\Delta_{\mathrm{d}}^{\mathrm{t}}$ and $\Delta_{\mathrm{w}}^{\mathrm{t}}$ over drying and wetting periods $T_{d}$ and $T_{w}$ are compared to trigger thresholds $\theta_{d r y}$ and $\theta_{\text {wet }}$. If the drying condition is not met, all egg drying development is reset to zero. If the wetting condition is not met, fully dry mature eggs remain at stage and do not hatch. Transovarial transmission in the virus by Aedes to their offspring is modelled via a further subdivision of the immature Aedes component into uninfected and infectious categories (Figure 1A).

The primary effects of temperature on vector population dynamics within this model are involved in determining the biting rate and daily survival probability of the mosquito. Three different survival probability parameterisations developed for LMM are available within LRVF (Table 2A).

Temperature-dependent biting rates can modify the overall rate of transmission within the system as well as impacting population dynamics due to the gonotrophic cycles of Aedes and Culex whereby ovipositioning follows the ingestion of a blood meal. For example, ( $T$ $\left.T_{g}\right) /\left(D_{g}+T-T_{g}\right)$ describes the gonotrophic cycle rate of the mosquito dependent on temperature, $T$, where $T_{g}$ is a temperature threshold and $D_{g}$ a degree-day threshold. This functional form includes the time taken for a blood meal to be taken (one day, independent of temperature) and the time for egg development, $D_{g} /\left(T-T_{g}\right)$ where $T$ represents temperature (Detinova, 1962). Published studies for Aedes and Culex mosquitoes indicate a gonotrophic cycle length of 2-3 days, consistent with the default LMM parameterisations of $T_{g}$ and $D_{g}$ at environmental temperatures of 26 and $44^{\circ} \mathrm{C}$ respectively (high humidity parameters, as given in Table 2A).

\section{Parameterisation}

This model has initially been developed based on RVF information gathered from its region of origin, the Rift Valley in eastern Africa. Opportunely, eastern Africa provides a suitable area to build the model not only due to its extensive history with RVF but also its diverse climatology and geography including a wide range of altitudes, two different rainy seasons, wetlands and large freshwater bodies. These incredibly diverse environmental conditions provide an ideal testing ground for development, parameterisation and validation of the LRVF model.

Parameter values for the vector component of the model (Table 2A) are taken from field studies in the literature related to Aedes and Culex where possible. Where these values are unavailable Anopheles-related parameters are used based on the original LMM model description (Hoshen and Morse, 2004). Livestock parameters (Table 2B) are based on cattle and sheep, and rates are measured with respect to time units of days. In places, parameterisation of the host module is based on the Ijara District community-based participatory survey that was conducted 
as part of the HEALTHY FUTURES project (Bett et al., 2013), and discussion with local experts at the International Livestock Research Institute (ILRI), Kenya. For a summary of LRVF host module parameterisation (Appendix). The natural lifespan of the livestock is used for the basal per capita mortality rate, $d_{i}$. The same natural mortality rate is assumed for both neonatal and adult livestock. The Maturation rate, $m$, is inversely proportional to the age at which infant livestock is no longer considered neonatal. A frequency dependent (mass action) transmission term is employed since it is expected that the contact structure is generally independent of population size for vector-borne pathogens where vectors far outnumber hosts (Keeling and Rohani, 2008). Therefore, using the transmission between neonatal hosts and infectious Aedes vectors in the biting stage of the gonotrophic cycle as an example, the force of infection is defined:

$$
\lambda_{x}^{A}=\beta_{x}^{A} \frac{Z_{I}^{A}}{X}
$$

with transmission rate

$$
\beta=-\kappa \log (1-s)
$$

where $s$ represents the susceptibility of the host, i.e., the probability of becoming infected following a bite from an infectious vector and $\kappa$ effectively represents a (temperature dependent) per capita biting rate:

A

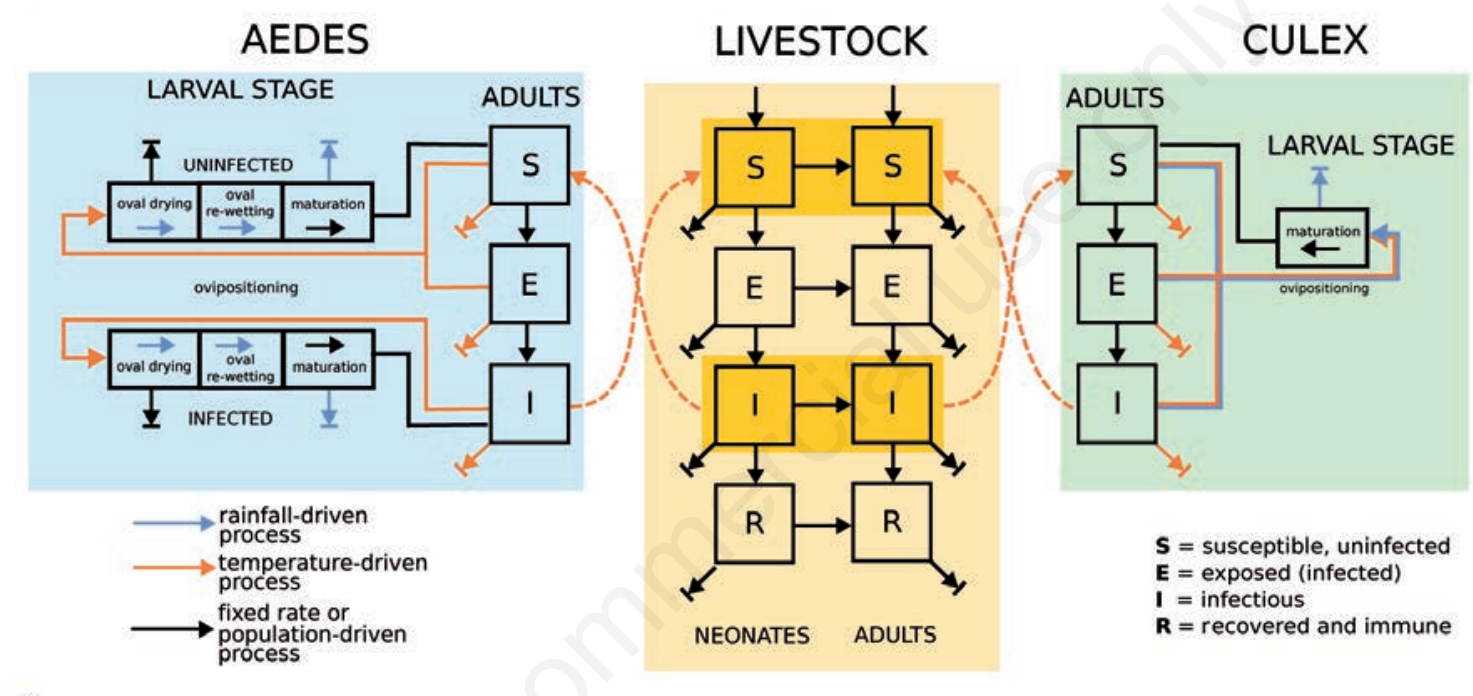

B

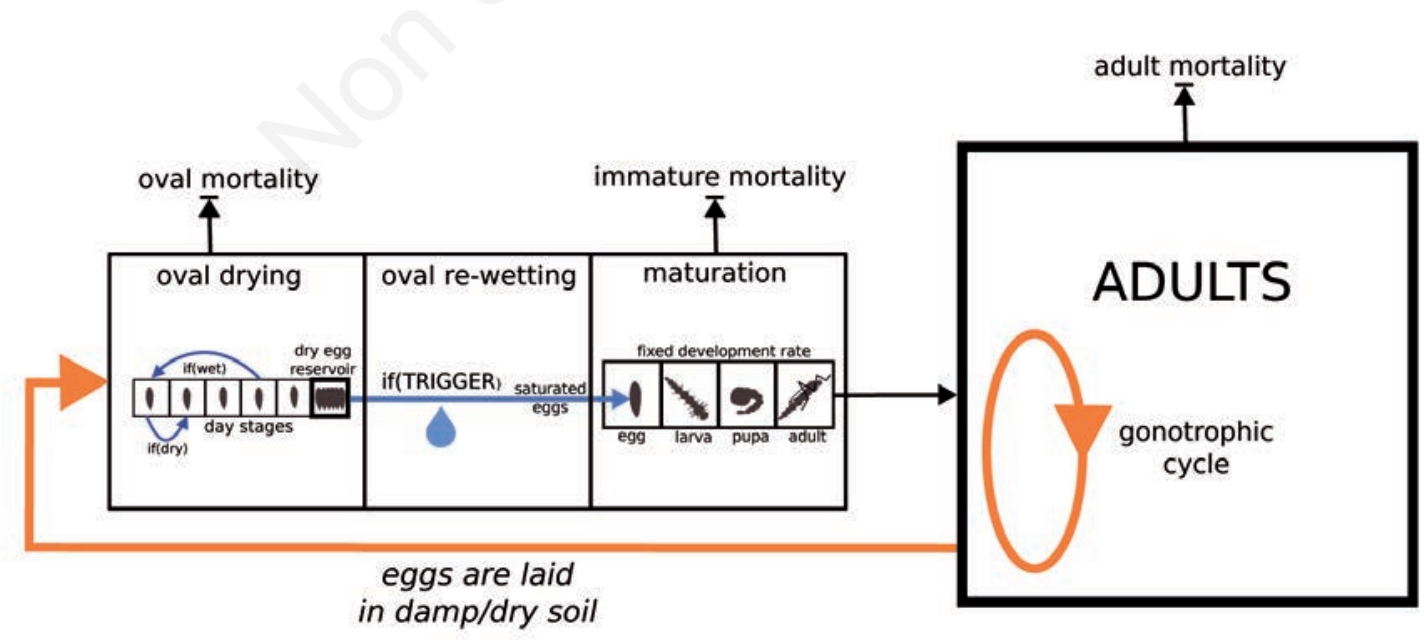

Figure 1. Schematic diagram of a prototype dynamic Rift Valley fever (RVF) model. The prototype Liverpool RVF model structure is described in (A) with separate vector components for Aedes and Culex and separate epidemiological compartments. Transmission is dependent on cross-infection between vectors and hosts. Climate dependent processes are indicated by different arrow colours for temperature (orange) and rainfall (blue). A detailed representation of the model structure for the Aedes mosquito larval stage is provided in (B) highlighting the rainfall trigger process required for Aedes emergence following a drying period. 
Table 2. Parameters of the Liverpool Rift Valley fever model for vector (A) and host (B) modules.

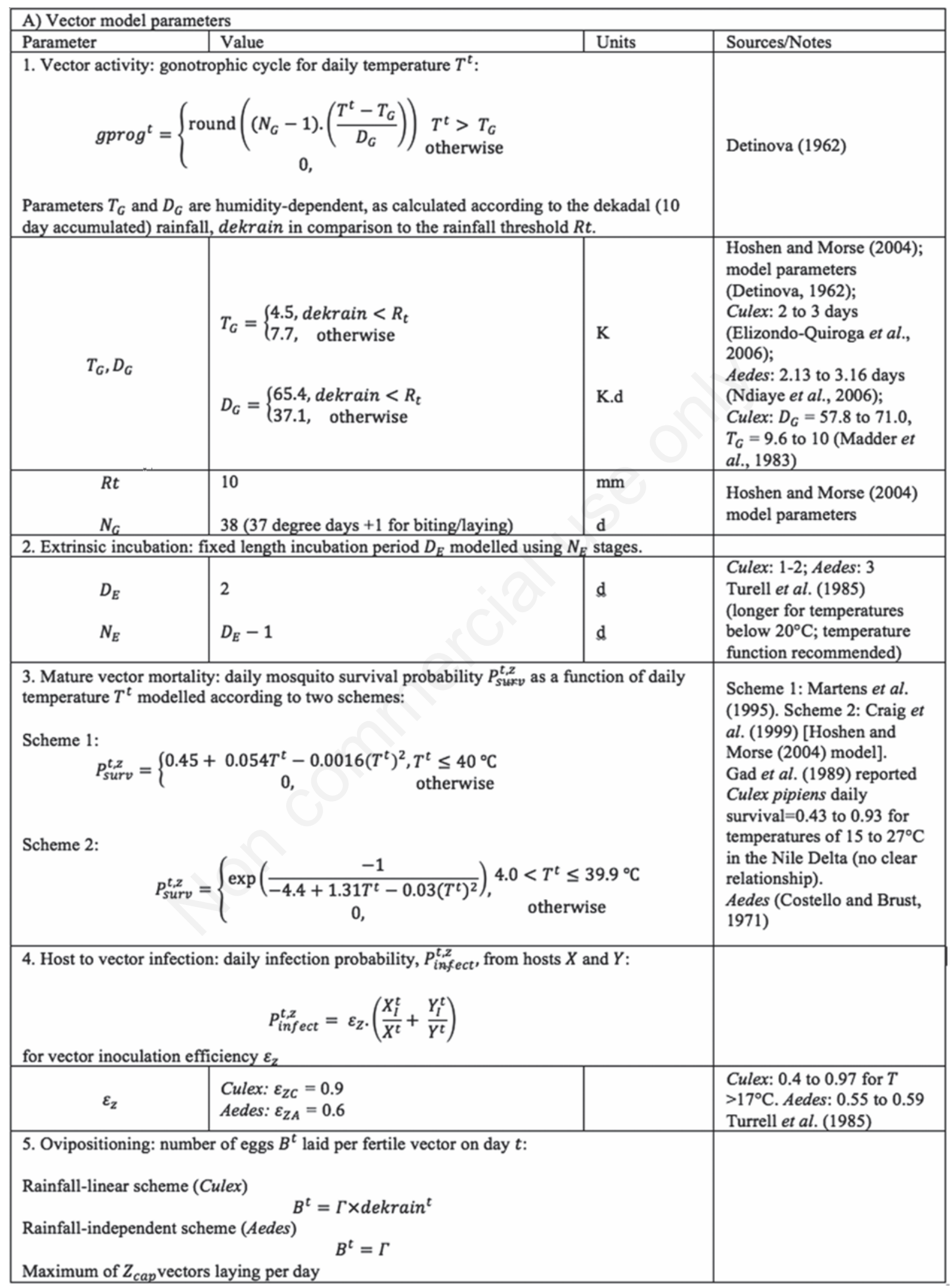

Continue on next page. 
Table 2. Continued from previous page

\begin{tabular}{|c|c|c|c|}
\hline$\Gamma$ & $\begin{array}{l}\Gamma_{A}=0.3(\text { Culex }) \\
\Gamma_{C}=10(\text { Aedes })\end{array}$ & Vector ${ }^{1} \mathrm{~mm}^{-1}$ & Calibrated \\
\hline$Z_{\text {cap }}$ & $10^{5}$ (both vectors) & Vector $^{1}$ & $\begin{array}{l}\text { Hoshen and Morse (2004) } \\
\text { model }\end{array}$ \\
\hline \multicolumn{4}{|c|}{$\begin{array}{l}\text { 6. Immature development: for larval stage of length } N_{L} \text { Aedes first undergo drying stage of } \\
\text { length } N_{E} \text { and a rewetting event according to thresholds } \theta_{\text {dry }} \text { and } \theta_{\text {wet }} \text { calculated over } \\
\text { periods } \tau_{d} \text { and } \tau_{w}\end{array}$} \\
\hline$N_{L}$ & $\begin{array}{l}15 \text { (Culex) } \\
4 \text { (Aedes) }\end{array}$ & d & $\begin{array}{l}\text { Culex: } 13 \text { to } 48 \text { days } \\
\text { (Olejnicek and Gelbic, } \\
\text { 2000; Rueda } \text { et al., } 1990) \text {; } \\
\text { Aedes: } 3 \text { to } 4 \text { days (Ndiaye } \\
\text { et al., 2006); } 5 \text { to } 7 \text { days } \\
\text { (Aida } \text { et al., 2011); } 6 \text { to } 10 \\
\text { days (Mohammed and } \\
\text { Chadee, 2011) }\end{array}$ \\
\hline $\begin{array}{c}N_{E} \\
\theta_{d r y}, \theta_{w e t} \\
\tau_{d}, \tau_{w}\end{array}$ & $\begin{array}{l}10 \\
\theta_{d r y}=5 ; \theta_{\text {wet }}=10 \\
\tau_{d}=6 ; \tau_{w}=2\end{array}$ & $\begin{array}{l}\mathrm{d} \\
\mathrm{mm} \\
\mathrm{d}\end{array}$ & Caminade et al. (2011) \\
\hline \multicolumn{4}{|c|}{$\begin{array}{l}\text { 7. Immature mortality: daily survival probability for larvae: } \\
P_{\text {larvsurv }}^{t, z}=L R_{0}+\frac{\left(\text { dekrain }^{t}+1\right)}{\left(\text { dekrain }^{t}+2\right)} \cdot L R_{f} \\
\text { Aedes eggs have fixed daily survival parameter } P_{\text {eggsurv }}\end{array}$} \\
\hline $\begin{array}{l}L R_{f} \\
L R_{0}\end{array}$ & $\begin{array}{l}1.0 \\
0.0\end{array}$ & & $\begin{array}{l}\text { Hoshen and Morse (2004) } \\
\text { model }\end{array}$ \\
\hline$P_{\text {eggsurv }}$ & 0.9 & & 0.878 (Aida et al., 2011) \\
\hline \multicolumn{4}{|l|}{ 8. Miscellaneous } \\
\hline $\begin{array}{c}\text { Transovarial } \\
\text { transmission factor } \varphi\end{array}$ & 1.0 (Aedes) & & $\begin{array}{l}0.114(0 \text { to } 1) \text { (Romoser } e t \\
\text { al., 2011) }\end{array}$ \\
\hline $\begin{array}{l}\text { Infected mosquitoes } \\
\text { added every } 10 \text { days. } \\
Z_{\text {itrickle }}^{\text {. }}\end{array}$ & 1.0 (both vectors) & & $\begin{array}{l}\text { Hoshen and Morse (2004) } \\
\text { model }\end{array}$ \\
\hline \multicolumn{4}{|l|}{ B) Host model parameters } \\
\hline Parameter & Value & Units & Source \\
\hline $\begin{array}{l}\text { Basal mortality rates: } \\
\qquad d_{x}, d_{y}\end{array}$ & $d_{x}=d_{y}=\frac{1}{365 \times 5.742}=4.77 \times 10^{-4}$ & $\mathrm{~d}^{-1}$ & (Bett et al., 2013) \\
\hline Maturation rate: $m$ & $m=\frac{1}{365 \times(2 / 9)}=1.23 \times 10^{-2}$ & $\mathrm{~d}^{-1}$ & Discussions with ILRI \\
\hline $\begin{array}{l}\text { Rates of infection: } \\
\beta_{x}^{A}, \beta_{x}^{C}, \beta_{y}^{A}, \beta_{y}^{C}\end{array}$ & $\begin{aligned} \beta_{x}^{A}= & \beta_{y}^{A} \\
= & \left\{\begin{array}{c}-0.005 \frac{T-T_{g}}{D_{g}+T-T_{g}} \log (1-1 / 6), T>T_{g} \\
0, \text { otherwise }\end{array}\right. \\
& \beta_{x}^{C}=\beta_{y}^{C} \quad\left\{\begin{array}{c}-0.25 \frac{T-T_{g}}{D_{g}+T-T_{g}}(1-1 / 6), T>T_{g} \\
0, \text { otherwise }\end{array}\right.\end{aligned}$ & $\mathrm{d}^{-1}$ & $\begin{array}{l}\text { (Detinova, 1962; Keeling } \\
\text { and Rohani, 2008) }\end{array}$ \\
\hline $\begin{array}{c}\text { Incubation parameters: } \\
\sigma_{x}, \sigma_{y} \\
\end{array}$ & $\sigma_{x}=\sigma_{y}=\frac{1}{3.5}=2.86 \times 10^{-1}$ & $\mathrm{~d}^{-1}$ & $\begin{array}{l}\text { (Turell et al. 1985; Gaff et } \\
\text { al. 2007; Niu et al., 2012) }\end{array}$ \\
\hline Recovery rates: $\gamma_{x}, \gamma_{y}$ & $\gamma_{x}=\gamma_{y}=\frac{1}{6.5}=1.54 \times 10^{-1}$ & $\mathrm{~d}^{-1}$ & $\begin{array}{l}\text { (Bird et al., 2009; Nfon et } \\
\text { al., 2012) }\end{array}$ \\
\hline $\begin{array}{l}\text { Infection-induced } \\
\text { mortality probabilities: } \\
\rho_{x}, \rho_{y}\end{array}$ & $\begin{array}{c}\rho_{x}=\frac{1}{3} \times 0.45+\frac{2}{3} \times 0.85=7.17 \times 10^{-1} \\
\rho_{y}=\frac{1}{3} \times 0.055+\frac{2}{3} \times 0.095=8.17 \times 10^{-2}\end{array}$ & I & (Bird et al., 2009) \\
\hline Birth rate: $b$ & $b=d_{x}=d_{y}$ & $\mathrm{~d}^{-1}$ & 1 \\
\hline Import rate: $c$ & $c=\frac{Y^{*}\left(d_{y}\left(d_{x}+m\right)-m b\right)}{\left(d_{x}+m\right)}$ & Host $\mathrm{d}^{-1}$ & I \\
\hline
\end{tabular}

ILRI, International Livestock Research Institute. 


$$
\kappa=\left\{\begin{array}{c}
L B I \frac{T-T_{g}}{D_{g}+T-T_{g}}, T>T_{g} \\
0, \text { otherwise }
\end{array}\right.
$$

The biting rate is proportional to the livestock blood index, or $L B I$, which indicates the proportion of mosquito bites assumed to be on cattle or sheep (rather than other mammals), and the gonotrophic cycle rate. For further information regarding the derivation of this transmission term see the Appendix. The incubation parameter, $\sigma_{i}$, is defined as the inverse of a 3.5-day latent period (Turell et al., 1985; Gaff et al., 2007; Niu et al., 2012) and the recovery rate is based on a 6.5 -day infectious period (Bird et al., 2009; Nfon et al., 2012). The infection-induced mortality probability, i.e., the probability of dying due to RVF infection before recovering, is based on case fatality rates (Bird et al., 2009).

\section{Climate data, epidemiological data, and model simulations}

Model simulations were driven using climate data for 1998 to 2010. A combination of ERA-Interim reanalysis (temperature) and Tropical

A
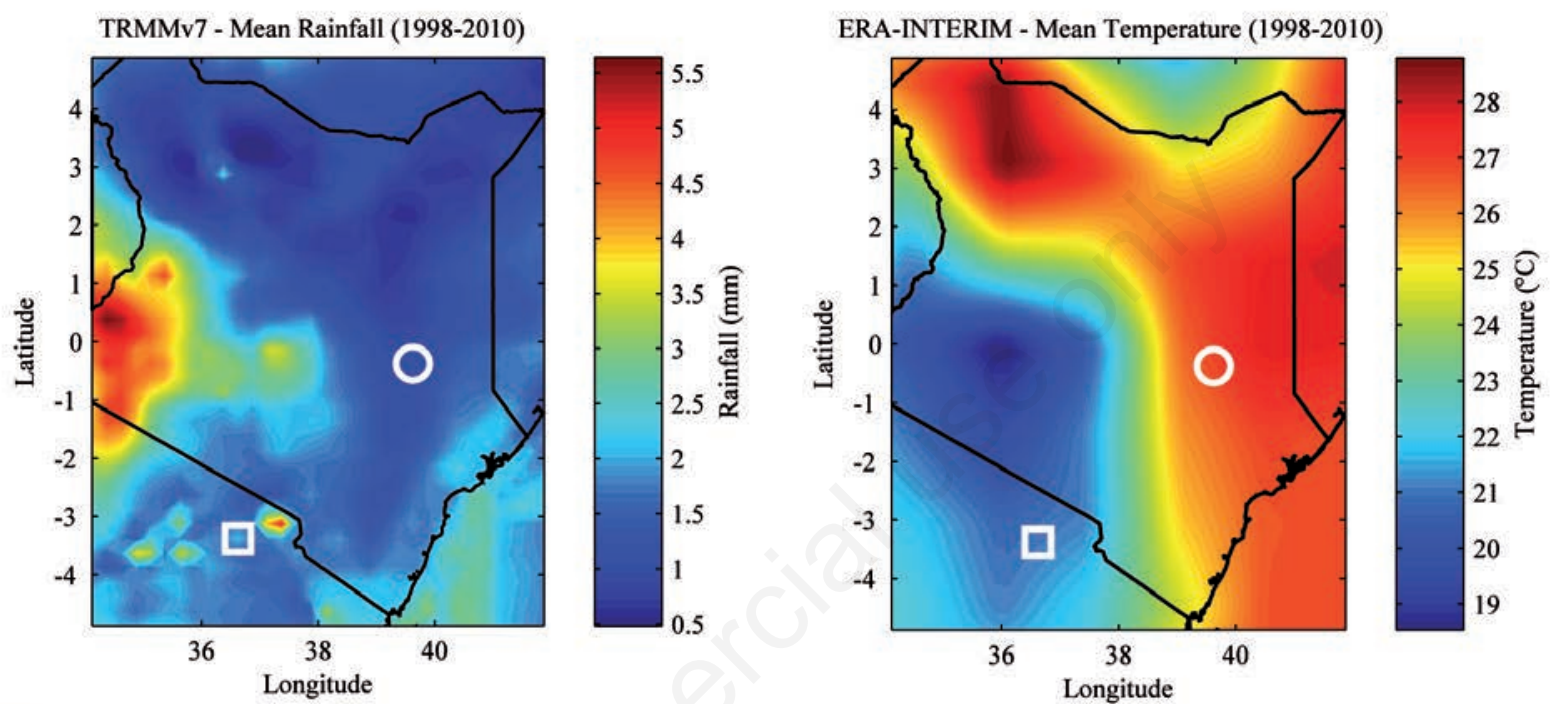

B
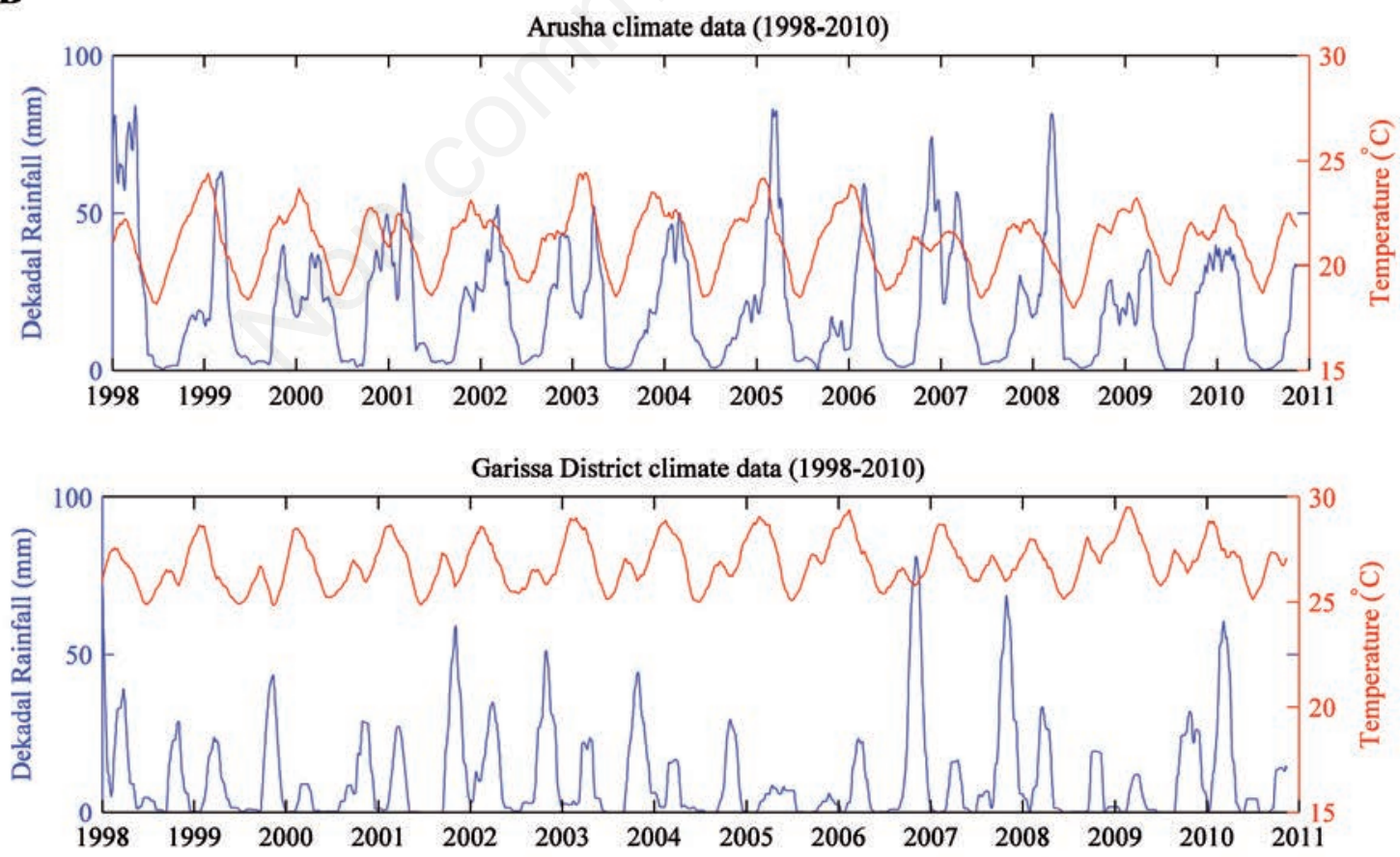

Figure 2. Rainfall and temperature conditions for Kenya and Arusha from 1998 to 2010. Mean climatic conditions for the period are plotted in (A) for the entire region with study sites marked for the Garissa District (circle) and Arusha (square). Time-series are also plotted in (B) for study sites. Fifty day smoothing has been applied to the daily time-series provided by ERA-Interim temperature and Tropical Rainfall Measuring Mission v7 data. 
Rainfall Measuring Mission (TRMM) (rainfall) satellite climate data were used. ERA-Interim (Dee et al., 2011) is a global atmospheric reanalysis dataset from January 1979 to the present day providing daily values for temperature in our model. The TRMM (Huffman et al., 2001) monitors tropical rainfall via satellite and provides a daily rainfall amount to LRVF. Climate data were extracted for the domain $34^{\circ} \mathrm{E}$ to $42^{\circ} \mathrm{E}, 5^{\circ} \mathrm{N}$ to $5^{\circ} \mathrm{S}$ (Kenya and NE Tanzania) at a resolution of $0.25^{\circ}$ and used to drive the LRVF model. The model state was initialised for 12 months using the input data for 1998.

Ideally, model calibration and validation would be carried out with reference to detailed fine temporal resolution epidemiological data of past RVF epizootics. In the absence of such records, calibration and structural validation of LRVF was achieved by comparison of the timing of peaks in the modelled disease transmission with training events for specific case studies based on the most severe RVF epizootics that occurred in both Kenya and Tanzania in 1997/98 and 2006/07 (Himeidan et al., 2014). The origins of these major outbreaks were the Garissa district, Kenya, and Arusha, Tanzania.

Peaks in infectious vector activity were used to calibrate model output. This metric is typically quantified by epidemiologists using the entomological inoculation rate (EIR) for the vector of the system (Kelly-Hope and McKenzie, 2009). The EIR of the Culex vector was a particular source of focus for the understanding of model dynamics. The motivation behind this is that Culex is the amplifying vector that, in the model, only shows significant spikes in population dynamics following flooding and a sizeable Culex EIR value can only be the result of a large population of Culex that has become infected via transmission from a substantial amount of infectious hosts. These factors are therefore indicative of an epizootic. In contrast, population surges of Aedes are less sensitive to sustained rainfall and waterlogged surfaces due to a more complex relationship with rainfall patterns, and the vertical transmission makes interpretation of EIR dynamics more complicated when compared to Culex.

\section{Results}

\section{Preliminary calibration and examination of the model for severe outbreak locations}

Rainfall is concentrated in the west of the region towards Lake Victoria while the temperature is highest in the relatively lowland areas of Kenya including the Garissa district (Figure 2A). A closer look at the specific study-sites of the Garissa district and Arusha in Figure 2B suggest that generally Arusha is wetter and cooler than the Garissa district over the study timescale.

Model dynamics were explored for these locations by varying the parameters governing the ovipositioning rates in Culex and Aedes, $\Gamma_{C}$ and $\Gamma_{\mathrm{A}}$, together with the host-vector transmission probability for Culex, $\varepsilon_{z c}$. The remaining model parameters were obtained from the literature for RVF, or, where unknown, from the default vector model setting used in the Hoshen and Morse (2004) model for Anopheles spp. malaria vectors. A final calibrated setting for $\Gamma_{C}, \Gamma_{A}$, and $\varepsilon_{\mathrm{zc}}$ was obtained by comparing the model peaks in Culex EIR with the timing of observed outbreaks in 1997/98 and 2006/07, adjusting the parameters such that both vectors could equally contribute to disease transmission, and that the 1997/98 and 2006/07 were resolved (as distinct from background variability). Figure 3 shows plots of EIR dynamics for both Aedes and Culex and RVF incidence versus time for the two regions, Garissa and Arusha, for the final setting. Incidence is defined here as the number of new cases per day. There is qualitative agreement between sig- nificant increases in LRVF incidence in these plots at the expected times (1997/98 and 2006/07) based on observations of major RVF epizootics. Note that mean incidence generally coincides with relatively wetter, cooler regions. Indeed, the lower magnitude of incidence in the Garissa district is due to the higher temperatures in this region, decreasing mosquito survival probability (for the more punitive default survival scheme used in this example). This is why only negligible Culex EIR is seen in the Garissa district for this parameterisation, and incidence peaks track peaks in Aedes EIR, which themselves are at least a factor of ten lower than the Aedes EIR for Arusha. Here, sustained rainfall and lower temperatures support higher and more frequent peaks in Aedes EIR. The circulation of the virus is amplified by large peaks in Culex EIR following climatic conditions that support large increases in the local Culex population (Figure 4) which translate to spikes in incidence of RVF in the livestock population.

The impact of mosquito survival scheme was further investigated by considering the mean LRVF model outputs over the region for the two alternative mosquito survival schemes described in Table 2A: the original default scheme (based on Martens et al., 1995), and a second scheme based on Craig et al. (1999). The two schemes yield similar survival probabilities at temperatures below approximately $20^{\circ} \mathrm{C}$, but for higher temperatures, the Craig et al. (1999) scheme is more permissive. Plots of mean EIR for Aedes and Culex together with mean incidence for immature livestock for the two schemes are shown in Figure 5. The western region of Kenya, where there is near-continuous year-round rainfall and Culex presence, dominates mean transmission by Culex for the default Martens scheme (Figure 5A). For the Craig scheme (Figure 5B) this region is still dominant but more extensive, and transmission is also seen on the Kenyan coast. The more permissive survival scheme of Craig et al. has a dramatic impact on Aedes, with much higher transmission in the high-temperature north-western and south-eastern regions. Significantly, the Craig et al. (1999) scheme results in higher levels of RVF cases in livestock in the Garissa district (approximately 0.5S, 39.5E), consistent with the large 1997/98 and 2006/07 outbreaks reported for this region. This result suggests that the Craig et al. (1999) scheme is a better approximation for survival of RVF vectors. LRVF model runs using this scheme will therefore be considered in the following results.

\section{Spatial distribution of Rift Valley fever transmission and the 2006/07 outbreak}

The 2006/07 RVF outbreak in Kenya followed heavy rainfall in November 2006 leading to flooding in north-eastern Kenya and Somalia. Growing evidence of an epidemic led to mosquito surveillance first in the Garissa District and then three other areas in eastern, central and western Kenya in the early months of 2007, as reported by Sang et al. (2010). These locations, each characterised by different environmental conditions, provide a useful focus for detailed exploration of the 2006/2007 outbreak as simulated by the LRVF model.

LRVF model variables for 2006/2007 season are shown in Figure 6. For the region around Garissa, rain begins in October and peaks in November, and this is associated with mass Aedes emergence (Figure $6 \mathrm{~A}$ and $\mathrm{B}$ ). Aedes transmission responds immediately (Figure 6C), indicating rapid emergence of infected Aedes as simulated by the model. The Garissa Culex population remains relatively low, peaking in January (Figure 6D), approximately two months after the peak rain. In January, the model-simulated Aedes EIR has already fallen to background levels around Garissa, and consequently the model does not simulate an amplification of RVF transmission by the Culex vector in this location. Interestingly, this seems consistent with the findings of Sang et al. (2010) who report that while both Aedes and Culex mosqui- 
toes were collected from sites around Garissa between December 2006 and March 2007, only Aedes were found to be infected with RVF, despite the presence in abundant numbers of Culex poicilipes, a known vector of RVF. The authors also report lower parity rates found for Culex spp. mosquitoes from Garissa compared to Aedes (69 and 95 to 100\% respectively in January), consistent with a delay in the emergence of Culex.

Around Kilifi (approximately 3.5S, 40E), the rainy season is longer and lasts from September to January. Modelled Aedes population and EIR peak in October, but, unlike Garissa, there are indications of transmission by Aedes through to January for this region. The simulated Culex population, while small for most of the year, exhibits a large increase in January (Figure 6D), and Culex EIR (Figure 6E) indicates some transmission by Culex in January and February with a corresponding secondary peak in immature livestock incidence (Figure 6F) in
February. Again this seems consistent with the findings of Sang et al. (2010) who report that both infected Culex and infected Aedes were collected from the Kilifi sites in January 2007.

Baringo (approximately 0.5N, 36E), in the Rift Valley, lies within the high rainfall western region for which the model simulates year-round Culex presence, with EIR peaking between September and January. This location is on the very edge of the area of modelled Aedes emergence (and corresponding transmission by Aedes), which occurs in October and November, and to a lesser extent, in February and April (not shown). Sang et al. (2010) report that mosquitoes collected in February 2007 around Baringo were predominately of the Mansonia spp., although Aedes, Culex and Anopheles spp. were also collected. From the model results we might have expected both infected Aedes and Culex to be present, but Sang et al. (2010) report infection was only

A
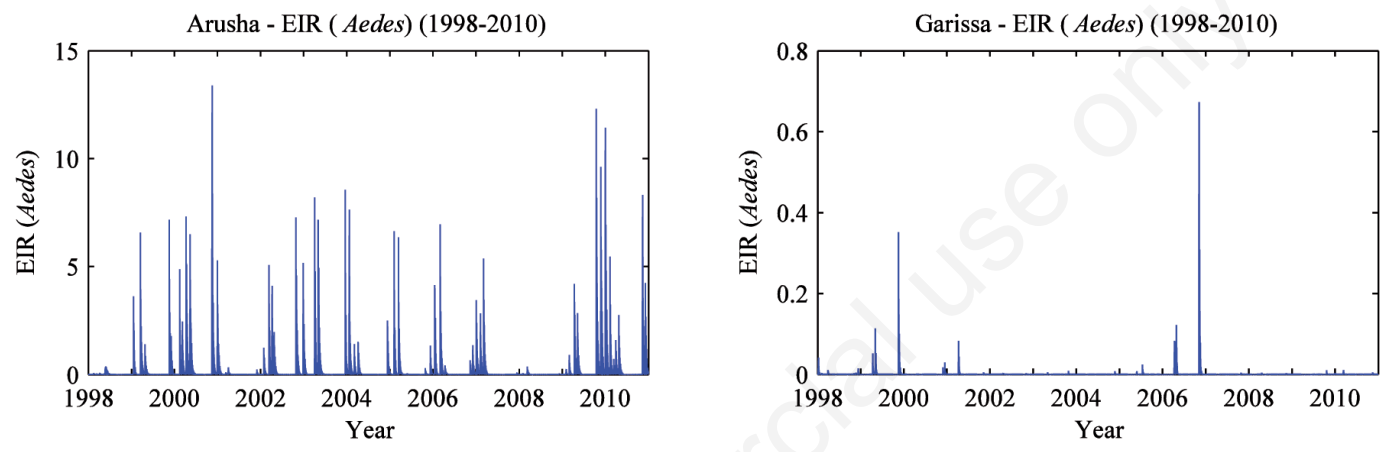

B
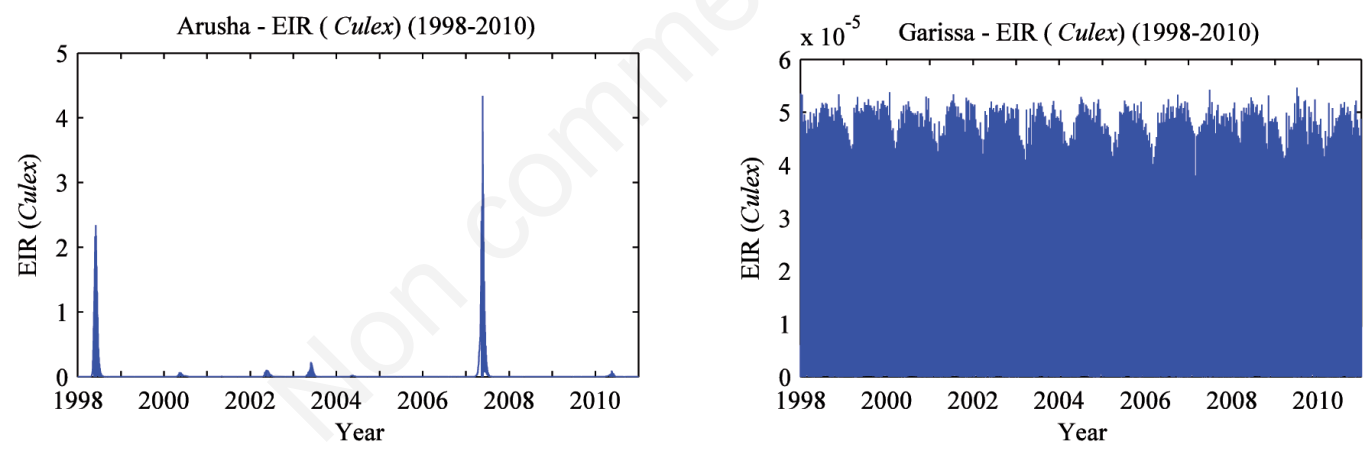

C
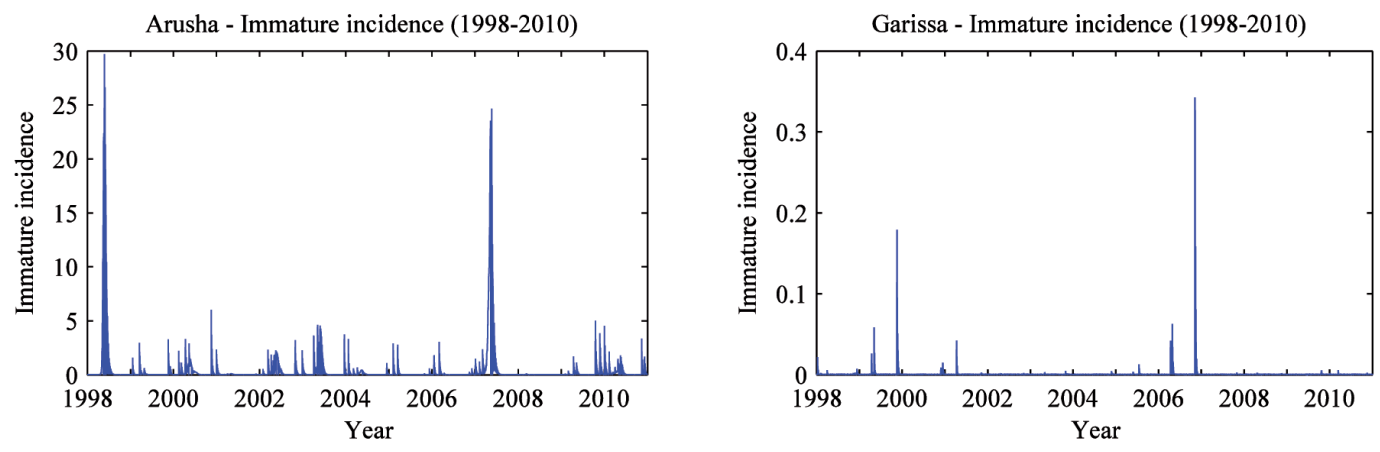

Figure 3. Liverpool Rift Valley fever model output for Aedes entomological inoculation rate (EIR) (A), Culex EIR (B) and immature incidence $(C)$ produced using ERA-Interim Temperature and Tropical Rainfall Measuring Mission v7 rainfall input values for the period 1998-2010 in the Garissa District, Kenya and Arusha, Tanzania. Parameter setting: $\Gamma_{C}=0.3, \Gamma_{A}=10 \mathrm{~mm}^{-1}$, $\varepsilon_{C}=0.9$, default mosquito survival (Martens et al., 1995). 
found in the Mansonia and Culex mosquitoes, with only small numbers of these being Culex. Finally, Kirinyaga, a highland region located on the southern slope of Mount Kenya, lies within a distinct area where for 2006/7 there are high levels of simulated Culex and low levels of Aedes. For 2006/7, the EIR plots (Figure 6C and E) indicate very little transmission of RVF by either vector, most likely because of the negative impact of cooler temperatures (around $18^{\circ} \mathrm{C}$ ) on the modelled vector biting rates. There is some agreement here of the model with the field data; Sang et al. (2010) reported that while both Aedes and Culex mosquitoes were collected at the sites round Kirinyaga in February 2007, the majority were Culex, and no RVF infections were detected.

\section{Discussion}

Transmission of the Rift Valley fever virus is sensitive to driving environmental factors and in particular the local climate. From major outbreaks to low-level transmission during inter-epizootic periods, climate impacts RVF transmission via the lifecycles and activity of the two chief vectors. The LRVF model distinguishes between two different genera of vector that transmit RVF: Aedes and Culex, as well as dividing the host module into mature and immature livestock categories due to significantly different case fatality ratios. Infection is indirect via interaction between the hosts and vectors whose populations are divided into classes based on their infection status. Recovered hosts acquire lifelong immunity. LRVF describes the epidemiology of hosts and vec- tors as determined by climate-dependent transmission parameters. Climate signal dependence is incorporated into the model by using observed daily temperature and rainfall values to drive the model, which then affect various rates including larval development, gonotrophic cycle, ovipositioning and mortality related parameters.

The climate-driven LRVF simulations presented here appear to correctly capture the timing and locations of the 1997/98 and 2006/07 outbreaks. Furthermore, the EIR and incidence dynamics do not simply track either or both of the vector population dynamics, highlighting the complexity of RVF transmission and its correlation with climate, and comparison with field data for $2006 / 07$ suggests the model is also capable of capturing the more sophisticated dynamics of infection in the vector population. That the model can produce these results without extensive local calibration and fine-tuning of parameter values is very encouraging. These results partly validate the structure and nature of the climate-epidemiology relationships inherent within LRVF. That is, the qualitative dynamics of the model, which are translated to epizootic characteristics, are features that result directly from the mathematical kinetic terms, network topology and driving climate data. These results are therefore not imposed by statistical data-fitting or simple correlative empirical relationships but from the description of underlying physical processes that contribute to RVF transmission and thus enhance our understanding of the epidemiology of epizootic susceptibility. The impact of RVF outbreaks can be devastating both economically, due to stock depletion and restriction of trade, as well as from a public health perspective. Improved understanding of the relationship between climate and RVF transmission can help local decision makers

A
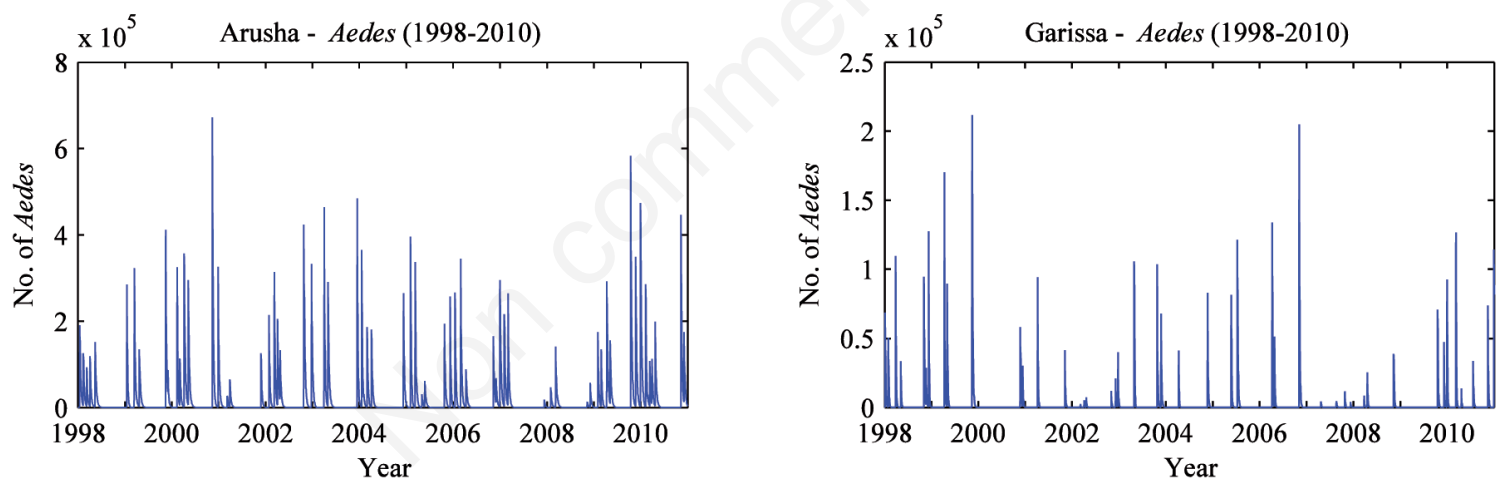

B
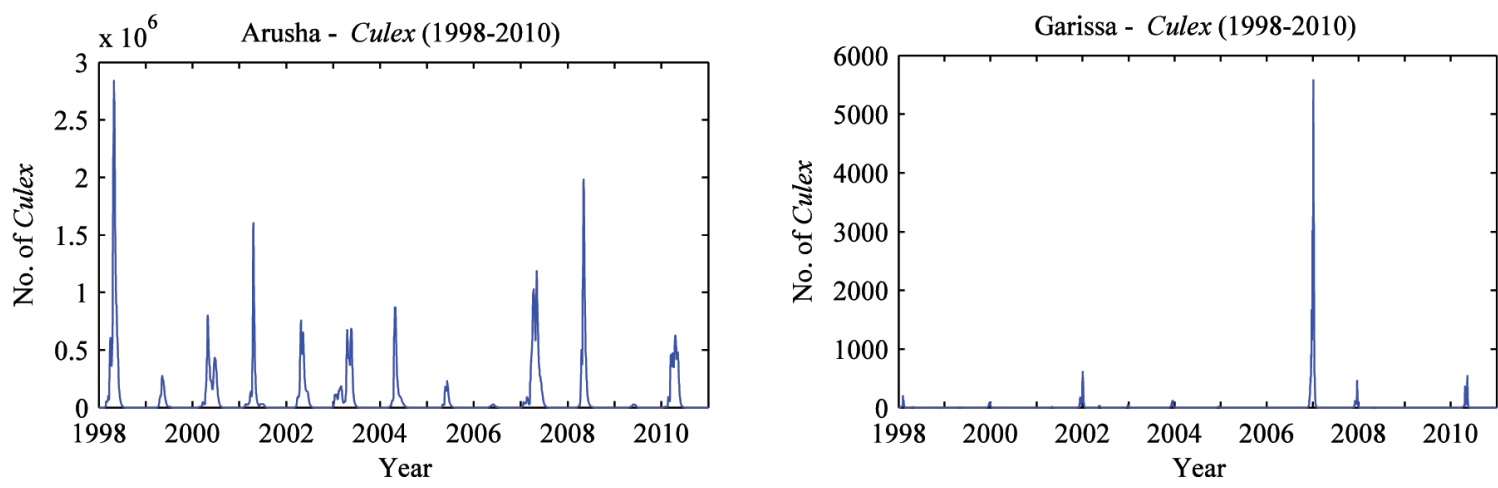

Figure 4. Liverpool Rift Valley fever model output for total Aedes (A) and Culex (B) population dynamics in the Garissa district and Arusha between 1998 and 2010. Parameter setting: $\Gamma_{C}=0.3, \Gamma_{A}=10 \mathrm{~mm}^{-1}, \varepsilon_{C}=0.9$, default mosquito survival (Martens et al., 1995). 
to anticipate and mitigate future epizootics. The inclusion of climate as the key input signal for these dynamics allows us to predict the potential impact on disease over a wide range of spatial and temporal scales, from using local weather forecasts for epizootic early warning to using long-term climate model projections to assess the impact of global climate change on RVF. Modelled outputs in combination with local knowledge will provide the most effective tools for anticipating infection risk appropriate to short-term decisions of health professionals and long-term policies of governments in susceptible countries.

Whether regions susceptible to increased RVF transmission in the future are capable of supporting a major outbreak depends on short timescale rainfall dynamics as well as the local vector population and state of host immunity. Since the model dynamics are essentially determined by dynamics of the climate input values, the quality of such data is vital in providing predictive response of sufficient accuracy to advise decision makers. Evaluating the quality and accuracy of climate data and climate models is a complex task in itself and previous studies have used ensemble methodologies in an attempt to address the issues of uncertainty between different sources of data (Caminade et al., 2014a; Leedale et al., 2016). This must be taken into consideration for

A

i

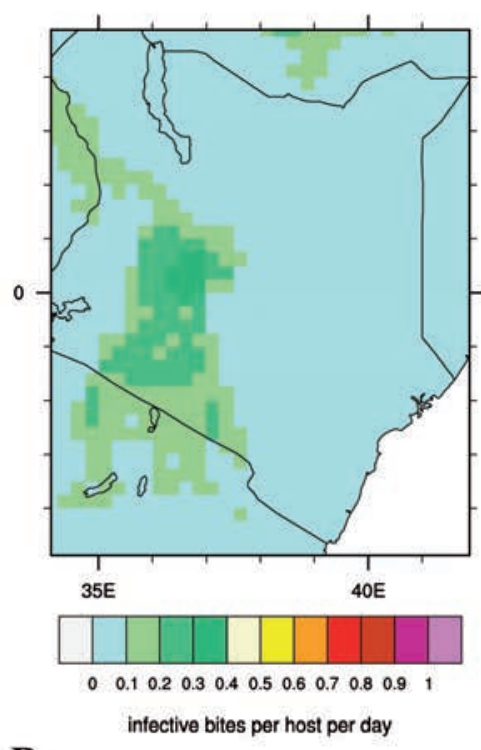

B

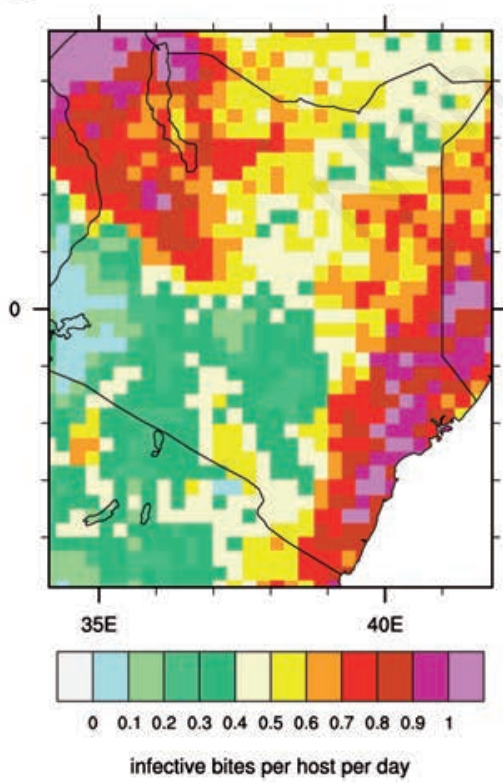

ii
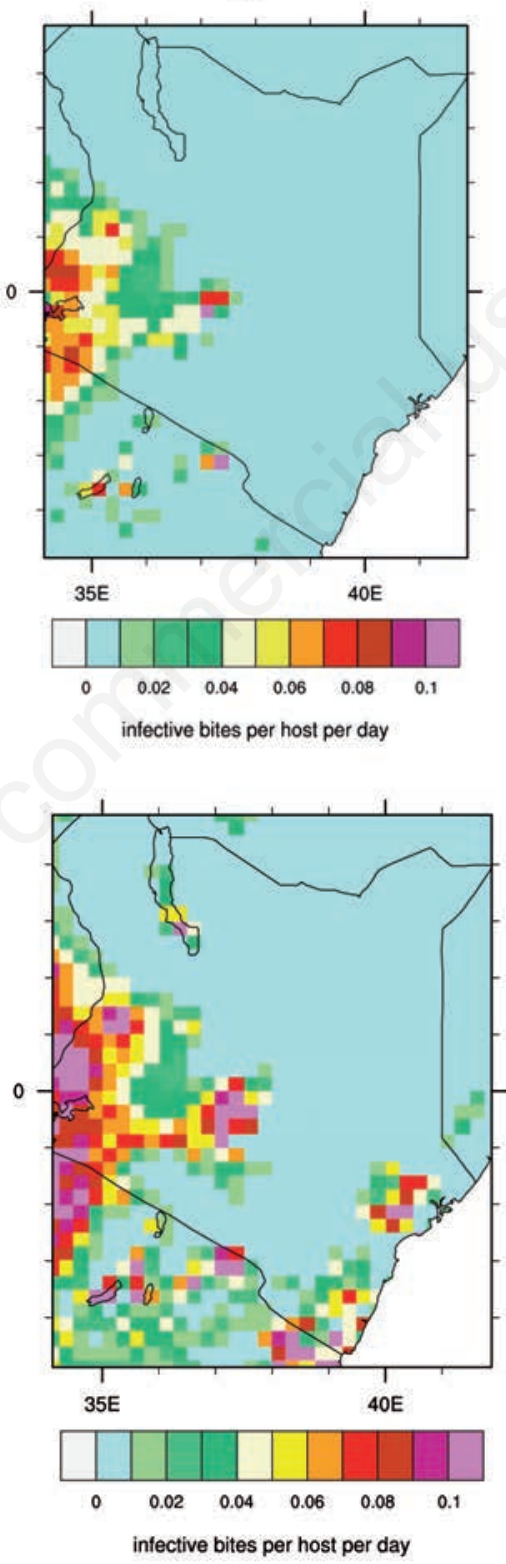

iii
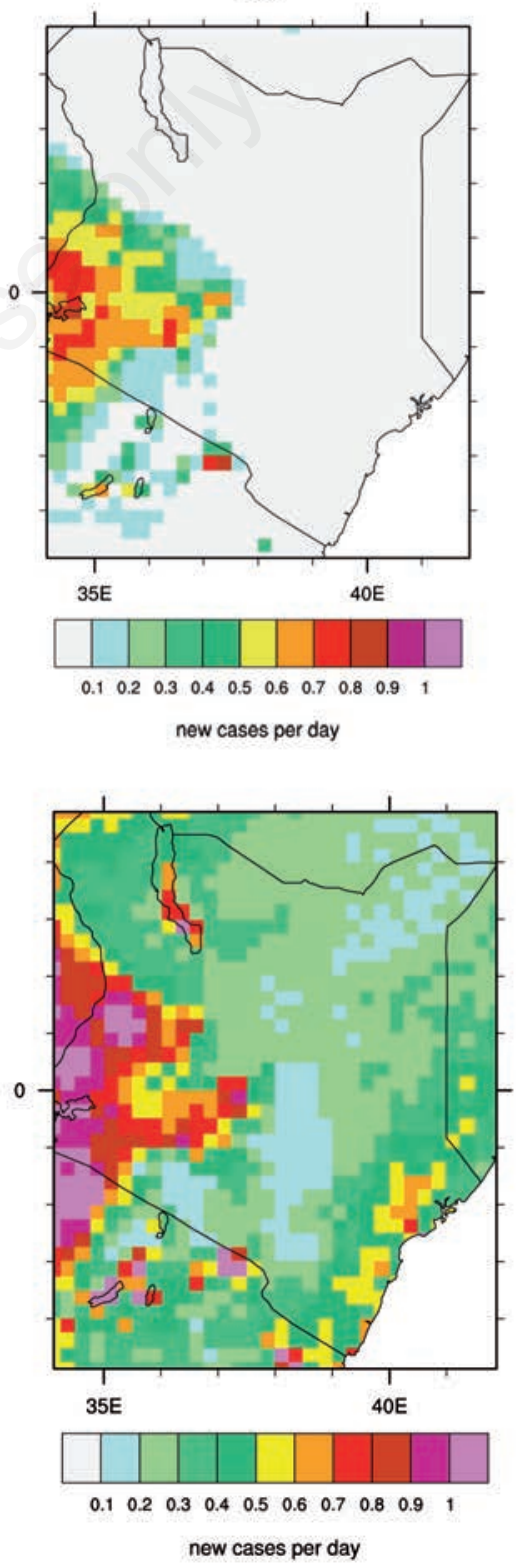

Figure 5. Impact of mosquito survival scheme on mean Liverpool Rift Valley fever model outputs for the period 1998-2010. A) Scheme based on Martens et al. (1995); B) scheme based on Craig et al. (1999). i) Aedes entomological inoculation rate (EIR), ii) Culex EIR, and iii) immature incidence. The other parameters were set to the values given in Table 2. 
A

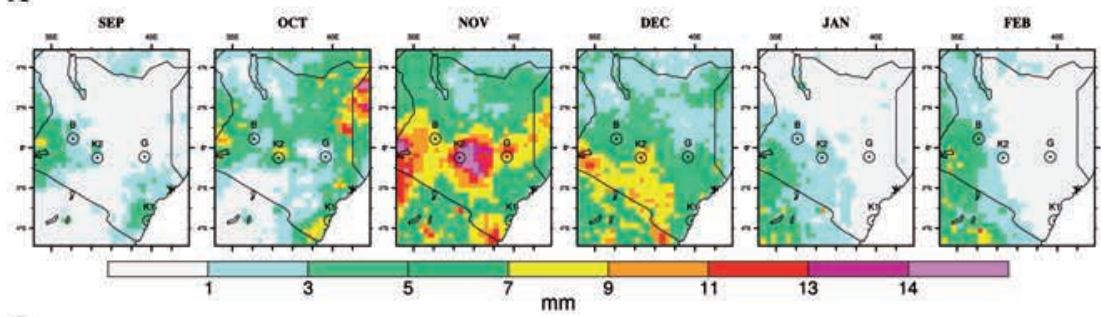

B

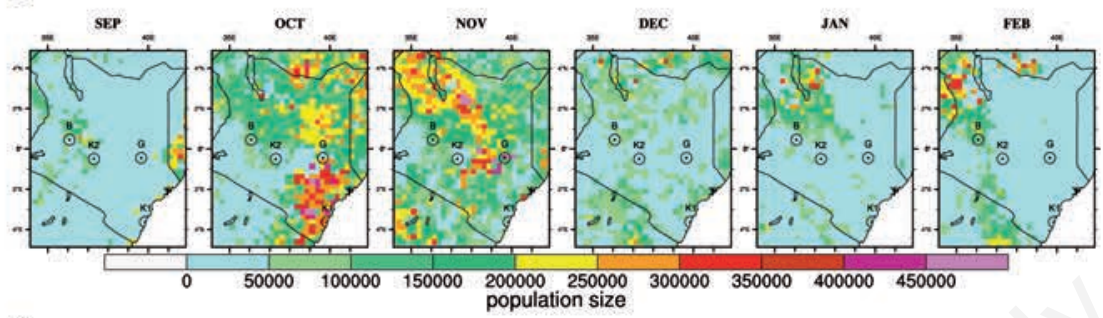

C

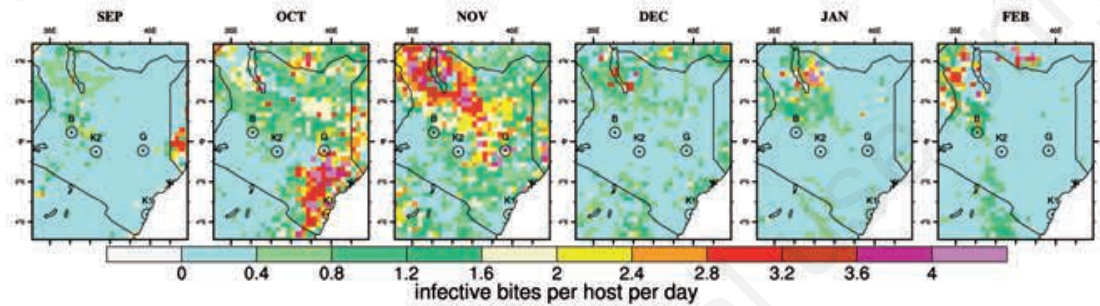

D

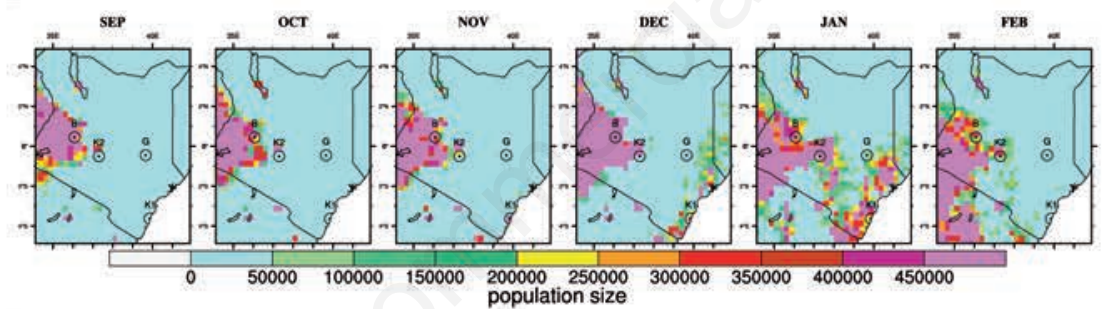

$\mathbf{E}$

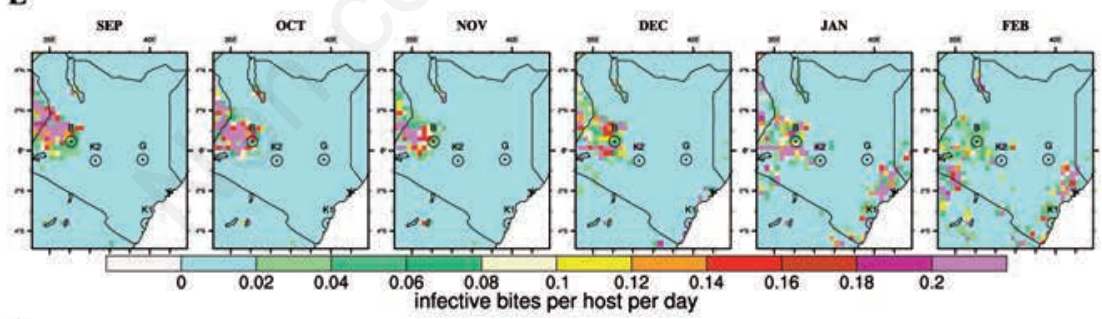

$\mathbf{F}$

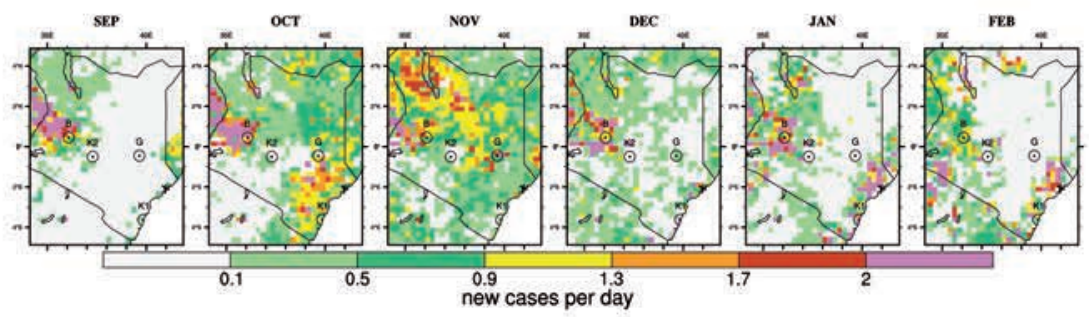

Figure 6. A) Tropical Rainfall Measuring Mission rainfall and B-F) Liverpool Rift Valley fever (RVF) model outputs for September 2006 to February 2007; B) Aedes population; C) Aedes entomological inoculation rate (EIR); D) Culex population; E) Culex EIR; and F) immature livestock RVF incidence. The Craig et al. (1999) survival scheme was utilised. The other model parameters were set to the calibrated values given in Table 2. Approximate centres of field study locations as described by Sang et al. (2010) are labelled as G (Garissa), K1 (Kilifi), B (Baringo) and K2 (Kirinyaga). 
future work involved in future scenarios and the impact of climate change. Despite initial parameterisation of this model being based in eastern Africa it is anticipated that LRVF will translate well in the future for studying areas outside of this region by refining parameter settings depending on local conditions and the ecological relationships between vector, host and environment.

A challenge in mechanistic disease modelling is in selecting a sufficiently complex formulation to adequately capture important disease dynamics without excessive calibration of unknown parameter values. This is particularly relevant for applications where disease data for calibration and validation is limited. Here, we base our model on two generic vectors, assuming that by doing so we can represent the mean contribution over sub-populations for which feeding preferences and (for Aedes spp.) vertical transmission characteristics will vary.

A further area where LRVF could become more refined and quantitatively accurate is the relative spatial densities of the host and two vectors whose population dynamics and breeding ground fluctuations have such a great impact on transmission events and epizootic behaviour. The inclusion of more explicit spatial information would be dependent on the model application, however; for climate change applications both historical information and future projections are required. For example, we would expect the spatial variation in human population settlements to impact on RVF transmission; however reliable estimates varying in space and time are not available at sufficient resolution over such a large region and long period. Recent research initiatives such as the Afripop project (Tatem et al., 2007) and the use of recent mobile phone technologies to monitor human population movements (Deville et al., 2014) are promising; and they should be included in future model development. Here, we have considered transmission potential given a continuous low-level background source of infection in the vector population, neglecting the impact of imported animals on RVF transmission. Livestock trading and movement are often considered a primary factor in the spread of the disease to previously unaffected areas (Di Nardo et al., 2014; Hassan et al., 2014), and ideally, future developments of the model would include detailed geo-referenced and timevarying animal movements; however, such historical datasets are not generally available for large areas of Africa.

The challenges of modelling Rift Valley fever lie within its complex vector-host structure and intermittent, epizootic nature. Compared to the relatively well-studied modelling of malaria for example, identifying and replicating the spatiotemporal transmission of RVF is an inherently more dynamically complex problem. This is partly due to the multiscale nature of RVF, where short timescale dynamics of severe RVF epizootics are contrasted with longer-term weather events, low-level enzootic activity and immunity prevalence. It is also relatively difficult to evaluate the current transmission and immunity states of the system when compared to other more endemic vector-borne disease such as malaria. These problems lead to difficulties in verifying mathematical models that aim to describe and quantify the epidemiological sequence of events of climate-dependent disease transmission covering large areas over long periods of time. Increased surveillance data is crucial during major epizootic events but sufficient inter-epizootic data may prove more difficult to acquire and justify to decision makers, especially among potential alternative RVF reservoirs.

\section{Conclusions}

Finally, by considering only the climate-related component of RVF risk, the model developed here can only form part of a suite of tools nec- essary to provide a comprehensive assessment of potential future RVF distributions and dynamics. Accurate prediction of the location and timing of epidemics, will require a combination of climatic risk together with detailed local serological and ecological information (Nanyingi et al., 2015). Furthermore, risk assessment must account quantitatively for both exposure via disease-enhancing environmental conditions, and vulnerability of an exposed population. A preliminary assessment of future RVF risk, using LRVF driven by climate projections in combination with a spatial vulnerability assessment for eastern Africa is described by Taylor et al. (2016). Future work will expand this assessment to include the impact of uncertainty in both RVF model formulation and climate projections on our understanding of the future potential impact of RVF.

\section{References}

Abdo-Salem S, Waret-Szkuta A, Roger F, Olive M-M, Saeed K, Chevalier V, 2011. Risk assessment of the introduction of Rift Valley fever from the Horn of Africa to Yemen via legal trade of small ruminants. Trop Anim Health Pro 43:471-80.

Aida HN, Dieng H, Satho T, Nurita A, Salmah MC, Miake F, Norasmah B, Ahmad AH, 2011. The biology and demographic parameters of Aedes albopictus in northern peninsular Malaysia. Asian Pac J Trop Biomed 1:472-7.

Anyamba A, Chretien J-P, Small J, Tucker CJ, Formenty PB, Richardson JH, Britch SC, Schnabel DC, Erickson RL, Linthicum KJ, 2009. Prediction of a Rift Valley fever outbreak. P Natl Acad Sci USA 106:955-9.

Anyamba A, Linthicum KJ, Small J, Britch SC, Pak E, de La Rocque S, Formenty P, Hightower AW, Breiman RF, Chretien J-P, 2010. Prediction, assessment of the Rift Valley fever activity in East and Southern Africa 2006-2008 and possible vector control strategies. Am J Trop Med Hyg 83:43-51.

Anyamba A, Linthicum KJ, Small JL, Collins KM, Tucker CJ, Pak EW, Britch SC, Eastman JR, Pinzon JE, Russell KL, 2012. Climate teleconnections and recent patterns of human and animal disease outbreaks. PLoS Neglect Trop D 6:e1465.

Bett B, Gachohi J, Mbotha D, 2013. Rift Valley fever/malaria study site analysis and major findings for Rift Valley fever and malaria transmission. Available from: https://cgspace.cgiar.org/ handle/10568/35204

Bicout D, Sabatier P, 2004. Mapping Rift Valley fever vectors and prevalence using rainfall variations. Vector-borne Zoonot 4:33-42.

Bird BH, Githinji JW, Macharia JM, Kasiiti JL, Muriithi RM, Gacheru SG, Musaa J0, Towner JS, Reeder SA, Oliver JB, 2008. Multiple virus lineages sharing recent common ancestry were associated with a large Rift Valley fever outbreak among livestock in Kenya during 2006-2007. J Virol 82:11152-66.

Bird BH, Ksiazek TG, Nichol ST, MacLachlan NJ, 2009. Rift Valley fever virus. J Am Vet Med Assoc 234:883-93.

Caminade C, Kovats S, Rocklov J, Tompkins AM, Morse AP, ColónGonzález F, Stenlund H, Martens P, Lloyd SJ, 2014a. Impact of climate change on global malaria distribution. P Natl Acad Sci USA 111:3286-91.

Caminade C, Ndione JA, Diallo M, MacLeod DA, Faye 0, Ba YM, Dia I, Morse AP, 2014b. Rift Valley fever outbreaks in Mauritania and related environmental conditions. Int J Environ Res 11:903-18.

Caminade C, Ndione JA, Kebe CMF, Jones AE, Danuor S, Tay S, Tourre Y, Lacaux JP, Vignolles C, Duchemin JB, 2011. Mapping Rift Valley 
fever and malaria risk over West Africa using climatic indicators. Atmos Sci Lett 12:96-103.

Chamchod F, Cantrell RS, Cosner C, Hassan AN, Beier JC, Ruan S, 2014. A modeling approach to investigate epizootic outbreaks and enzootic maintenance of Rift Valley fever virus. B Mathl Biol 76:2052-72.

Costello RA, Brust RA, 1971. Longevity of Aedes-vexans diptera-culicidae under different temperatures and relative humidities in laboratory. J Econ Entomol 64:324-5.

Craig MH, Snow RW, Le Sueur D, 1999. A climate-based distribution model of malaria transmission in sub-Saharan Africa. Parasitol Today 15:105-11.

Daubney R, Hudson JR, Garnham PC, 1931. Enzootic hepatitis or Rift Valley fever. An undescribed virus disease of sheep cattle and man from East Africa. J Pathol Bacteriol 34:545-79.

Davies FG, Highton RB, 1980. Possible vectors of Rift Valley fever in Kenya. T Roy Soc Trop Med H 74:815-6.

Dee DP, SM Uppala, AJ Simmons, P Berrisford, P Poli, S Kobayashi, U Andrae, M A Balmaseda, G Balsamo, P Bauer, 2011. The ERAInterim reanalysis: configuration and performance of the data assimilation system. Q J Roy Meteor Soc 137:553-97.

Detinova TS, 1962. Age grouping methods in Diptera of medical importance with special reference to some vectors of malaria. Monogr Ser World Health Organ 47:13-191.

Deville P, Linard C, Martin S, Gilbert M, Stevens FR, Gaughan AE, Blondel VD, Tatem AJ, 2014. Dynamic population mapping using mobile phone data. P Natl Acad Sci USA 111:15888-93.

Di Nardo A, Rossi D, Saleh SM, Lejlifa SM, Hamdi SJ, Di Gennaro A, Savini G, Thrusfield MV, 2014. Evidence of rift valley fever seroprevalence in the Sahrawi semi-nomadic pastoralist system, Western Sahara. BMC Vet Res 10:92.

Elizondo-Quiroga A, Flores-Suarez A, Elizondo-Quiroga D, PonceGarcia G, Blitvich BJ, Contreras-Cordero JF, Gonzalez-Rojas JI, Mercado-Hernandez R, Beaty BJ, Fernandez-Salas I, 2006. Gonotrophic cycle and survivorship of Culex quinquefasciatus (Diptera: Culicidae) using sticky ovitraps in Monterrey, northeastern Mexico. J Am Mosquito Contr 22:10-4.

Faye 0, Diallo M, Diop D, Bezeid OE, Bâ H, Niang M, Dia I, Mohamed SAO, Ndiaye K, Diallo D, 2007. Rift Valley fever outbreak with EastCentral African virus lineage in Mauritania, 2003. Emerg Infect Dis 13:1016.

Fischer EAJ, Boender G-J, Nodelijk G, de Koeijer AA, Van Roermund HJ, 2013. The transmission potential of Rift Valley fever virus among livestock in the Netherlands: a modelling study. Vet Res 44:58.

Fontenille D, Traore-Lamizana M, Diallo M, Thonnon J, Digoutte JP, Zeller HG, 1998. New vectors of Rift Valley fever in West Africa. Emerg Infect Dis 4:289.

Gad AM, Feinsod FM, Soliman BA, El Said S, 1989. Survival estimates for adult Culex pipiens in the Nile Delta. Acta Trop 46:173-9.

Gaff HD, Hartley DM, Leahy NP, 2007. An epidemiological model of Rift Valley fever. Electron J Differ Equ 2007:1-12.

Gerdes GH, 2002. Rift valley fever. Vet Clin N Am-Food A 18:549-55.

Hassan OA, Ahlm C, Evander M, 2014. A need for one health approachlessons learned from outbreaks of Rift Valley fever in Saudi Arabia and Sudan. Infect Ecol Epidemiol 2014:4.

Himeidan YE, Kweka EJ, Mahgoub MM, El Rayah EA, Ouma J0, 2014. Recent outbreaks of Rift Valley Fever in East Africa and the Middle East. Front Public Health 2014:169.

Hoshen MB, Morse AP, 2004. A weather-driven model of malaria transmission. Malaria J 3:32.

Huffman GJ, Adler RF, Morrissey MM, Bolvin DT, Curtis S, Joyce R,
McGavock B, Susskind J, 2001. Global precipitation at one-degree daily resolution from multisatellite observations. J Hydrometeorol 2:36-50.

Jupp PG, Kemp A, Grobbelaar A, Leman P, Burt FJ, Alahmed AM, Mujalli D, Khamees M, Swanepoel R, 2002. The 2000 epidemic of Rift Valley fever in Saudi Arabia: mosquito vector studies. Med Vet Entomol 16:245-52.

Keeling MJ, Rohani P, 2008. Modeling infectious diseases in humans and animals. Princeton University Press, Princeton, NJ, USA.

Kelly-Hope LA, McKenzie FE, 2009. The multiplicity of malaria transmission: a review of entomological inoculation rate measurements and methods across sub-Saharan Africa. Malaria J 8:19.

Linthicum KJ, Davies FG, Kairo A, Bailey CL, 1985. Rift Valley fever virus (family Bunyaviridae, genus Phlebovirus). Isolations from Diptera collected during an inter-epizootic period in Kenya. J Hygiene 95:197-209.

Leedale J, Tompkins AM, Caminade C, Jones AE, Nikulin G, Morse AP, 2016. Projecting malaria hazard from climate change in eastern Africa using large ensembles to estimate uncertainty. Geospat Health 11:393.

Linthicum KJ, Anyamba A, Tucker CJ, Kelley PW, Myers MF, Peters CJ, 1999. Climate and satellite indicators to forecast Rift Valley fever epidemics in Kenya. Science 285:397-400.

Madder D, Surgeoner G, Helson B, 1983. Number of generations, egg production, and developmental time of Culex pipiens and Culex restuans (Diptera: Culicidae) in southern Ontario. J Med Entomol 20:275-87.

Martens WJM, Jetten TH, Rotmans J, Niessen LW, 1995. Climate change and vector-borne diseases: a global modelling perspective. Glob Environ Change 5:195-209.

Meegan JM, Bailey CL, 1988. Rift valley fever. The arboviruses. Epidemiol Ecol 4:51-76.

Mohammed A, Chadee DD, 2011. Effects of different temperature regimens on the development of Aedes aegypti (L.) (Diptera: Culicidae) mosquitoes. Acta Trop 119:38-43.

Mondet B, Diaïté A, Ndione J, Fall AG, Chevalier V, Lancelot R, Ndiaye M, Ponçon N, 2005. Rainfall patterns and population dynamics of Aedes (Aedimorphus) vexans arabiensis, Patton 1905 (Diptera: Culicidae), a potential vector of Rift Valley Fever virus in Senegal. J Vector Ecol 30:102.

Mpeshe SC, Haario H, Tchuenche JM, 2011. A mathematical model of Rift Valley fever with human host. Acta Biotheor 59:231-50.

Nanyingi MO, Munyua P, Kiama SG, Muchemi GM, Thumbi SM, Bitek A0, Bett B, Muriithi RM, Njenga MK, 2015. A systematic review of Rift Valley Fever epidemiology 1931-2014. Infect Ecol Epidemiol 2015:5.

Nderitu L, Lee JS, Omolo J, Omulo S, O'Guinn ML, Hightower A, Mosha F, Mohamed M, Munyua P, Nganga Z, 2011. Sequential Rift Valley fever outbreaks in eastern Africa caused by multiple lineages of the virus. J Infect Dis 203:655-65.

Ndiaye PI, Bicout DJ, Mondet B, Sabatier P, 2006. Rainfall triggered dynamics of Aedes mosquito aggressiveness. J Theor Biol 243:222-9.

Ndione JA, Besancenot JP, Lacaux JP, Sabatier P, 2003. Environment and epidemiology of Rift Valley fever in the lower basin of the Senegal river. Envir Risque Sante 2:176-82.

Ndione JA, Diop M, Lacaux JP, Gaye AT, 2008. Rainfall intraseasonal variability and Rift Valley fever emergence in Senegal river basin: new considerations. Climatologie 5:83-97.

Nfon CK, Marszal P, Zhang S, Weingartl HM, 2012. Innate immune response to Rift Valley fever virus in goats. PLoS Neglect Trop Dis 6:e1623. 
Nguku PM, Sharif S, Mutonga D, Amwayi S, Omolo J, Mohammed 0, Farnon EC, Gould LH, Lederman E, Rao C, 2010. An investigation of a major outbreak of Rift Valley fever in Kenya: 2006-2007. Am J Trop Med Hyg 83:5-13.

Niu T, Gaff HD, Papelis YE, Hartley DM, 2012. An epidemiological model of Rift Valley fever with spatial dynamics. Comput Math Method M 2012:138757.

Olejnícek J, Gelbic I, 2000. Differences in response to temperature and density between two strains of the mosquito, Culex pipiens molestus Forskal. J Vector Ecol 25:136-45.

Pepin M, Bouloy M, Bird BH, Kemp A, Paweska J, 2010. Rift Valley fever virus (Bunyaviridae: Phlebovirus): an update on pathogenesis, molecular epidemiology, vectors, diagnostics and prevention. Vet Res 41:61.

Peyre M, Chevalier V, Abdo-Salem S, Velthuis A, Antoine Moussiaux N, Thiry E, Roger F, 2014. A systematic scoping study of the socio economic impact of Rift Valley Fever: research gaps and needs. Zoonoses Public Hlth 62:309-25.

Porphyre T, Bicout DJ, Sabatier P, 2005. Modelling the abundance of mosquito vectors versus flooding dynamics. Ecol Model 183:173-81.

Rolin AI, Berrang-Ford L, Kulkarni MA, 2013. The risk of Rift Valley fever virus introduction and establishment in the United States and European Union. Emerg Microbes Infect 2:e81.

Romoser WS, Oviedo MN, Lerdthusnee K, Patrican LA, Turell MJ, Dohm DJ, Linthicum KJ, Bailey CL, 2011. Rift Valley fever virus-infected mosquito ova and associated pathology: possible implications for endemic maintenance. Res Rep Trop Med 2:121-7.

Rueda LM, Patel KJ, Axtell RC, Stinner RE, 1990. Temperature-dependent development and survival rates of Culex quinquefasciatus and Aedes aegypti (Diptera: Culicidae). J Med Entomol 27:892-8.

Sallam MF, Al Ahmed AM, Abdel-Dayem MS, Abdullah MA, 2013.
Ecological niche modeling and land cover risk areas for rift valley fever vector, Culex tritaeniorhynchus giles in Jazan, Saudi Arabia. PLoS One 8:e65786.

Sang R, Kioko E, Lutomiah J, Warigia M, Ochieng C, O'Guinn M, Lee JS, Koka H, Godsey M, Hoel D, 2010. Rift Valley fever virus epidemic in Kenya, 2006/2007: the entomologic investigations. Am J Trop Med Hyg 83:28-37.

Soti V, Tran A, Degenne P, Chevalier V, Lo Seen D, Thiongane Y, Diallo M, Guégan J-F, Fontenille D, 2012. Combining hydrology and mosquito population models to identify the drivers of Rift Valley fever emergence in semi-arid regions of West Africa. PLoS Neglect Trop D 6:e1795.

Tatem AJ, Noor AM, Von Hagen C, Di Gregorio A, Hay SI, 2007. High resolution population maps for low income nations: combining land cover and census in East Africa. PLoS One 2:e1298.

Taylor D, Hagenlocher M, Jones AE, Kienberger S, Leedale J, Morse AP, 2016. Environmental change and Rift Valley fever in eastern Africa: projecting beyond HEALTHY FUTURES. Geospat Health 11:387.

Turell MJ, Rossi CA, Bailey CL, 1985. Effect of extrinsic incubation temperature on the ability of Aedes taeniorhynchus and Culex pipiens to transmit Rift Valley fever virus. Am J Trop Med Hyg 34:1211-8.

Wilson ML, 1994. Rift Valley Fever virus ecology and the epidemiology of disease emergence. Ann NY Acad Sci 740:169-80.

Xue L, Scott HM, Cohnstaedt LW, Scoglio C, 2012. A network-based meta-population approach to model Rift Valley fever epidemics. J Theor Biol 306:129-44.

Zeller HG, Fontenille D, Traore-Lamizana M, Thiongane Y, Digoutte JP, 1997. Enzootic activity of Rift Valley fever virus in Senegal. Am J Trop Med Hyg 56:265-72. 